Research Article

\title{
Finite Element Modeling of Slip Insert Geometric Grip Optimization for Oil Well Drill Pipes
}

\author{
Liping Tang $(\mathbb{D}$, Baolin Guo $\mathbb{D}$, and Xiaohua Zhu $\mathbb{( D}$ \\ School of Mechatronic Engineering, Southwest Petroleum University, Chengdu 610500, China \\ Correspondence should be addressed to Liping Tang; lipingtang@swpu.edu.cn and Xiaohua Zhu; zhuxh@swpu.edu.cn
}

Received 18 January 2020; Revised 13 April 2020; Accepted 6 May 2020; Published 10 June 2020

Academic Editor: Emilio Turco

Copyright (C) 2020 Liping Tang et al. This is an open access article distributed under the Creative Commons Attribution License, which permits unrestricted use, distribution, and reproduction in any medium, provided the original work is properly cited.

Drilling is being used to access ever-deeper oil and gas reservoirs, thereby presenting various challenges to the design and operation of down-hole tools. Slip inserts are suspension devices that are used to lower the drill pipe into the borehole and lift it to the wellhead, and their performance determines the extended depth of the borehole. In this paper, based on the field and laboratory test of the slip system, parameter sensitivity analysis is applied to the performance of a slip insert to guide the design of the latter. First, a mechanical model is developed of the drill pipe with the slip insert acting on it, and the stress acting on the drill pipe is analyzed theoretically by regarding the drill pipe as a thick-walled cylinder. Next, a numerical model is established to investigate how the slip-insert structure influences the drill-pipe stress, wherein the drill-pipe diameter is $5^{\prime \prime}$ and the axial load is 180 tons. Finally, the results of a series of numerical simulations are presented. For the present slip insert and drill pipe, the optimum slip-insert parameter values are a front-rake angle of $70^{\circ}$, a back-rake angle of $30^{\circ}$, a tooth height of $2 \mathrm{~mm}$, and zero chamfer.

\section{Introduction}

The energy crisis presents countries with serious challenges, increasing the possibilities for rising inflation, declining economic growth, increasing unemployment, and lost investment [1]. Because of rapid industrial development, the global demand for energy has risen sharply, and the amount of fossil energy production is insufficient to meet that demand [2]. Typical fossil fuels, oil, and gas are generally regarded as nonrenewable resources despite the fact that they are being formed continually [3]. Because of the continuous exhaustion of shallow oil and gas resources, the exploration and exploitation of oil and gas reservoirs are turning to ever-deeper resources [4], such as deep-water oil and gas. Constructing wells in these extreme conditions presents considerable challenges to the current technology of the oil industry, forcing the industry to develop new technologies to reach the target depths [5]. A critical technique for addressing the challenges of exploiting deep resources is tripping the drill pipe (DP) in and out of the well bore [6].
A DP is necessary for drilling a well, and the mechanical properties of the former are especially important for the safety of the drilling process and equipment [7]. During the process of drilling, the operations of lowering the DP to the bottom of the well and lifting it to the wellhead are accomplished by support or suspension devices known collectively as the slip system $[8,9]$. Figure 1 shows the schematic of a drilling system with a slip system. A typical slip system comprises (i) slip inserts that have tooth-like curved grippers arranged on their inner surfaces to grasp the DP and (ii) a slip body whose outer surface is tapered to fit the tapered face of the bushing bowl located in the rotary table [10]. The outer surface of the slip body is wedgeshaped, with the outer diameter of the upper end being greater than that of the lower end. The slip inserts are fixed or inserted into the slip body and can be replaced if they fail. The slip body responds to the axial tension load that is supported by the slip inserts and generates radial pressure on the DP being supported [11]. Under the corresponding radial force, the slip inserts hold the DP by embedding slightly into the DP when fully engaged [12]. Unfortunately, 


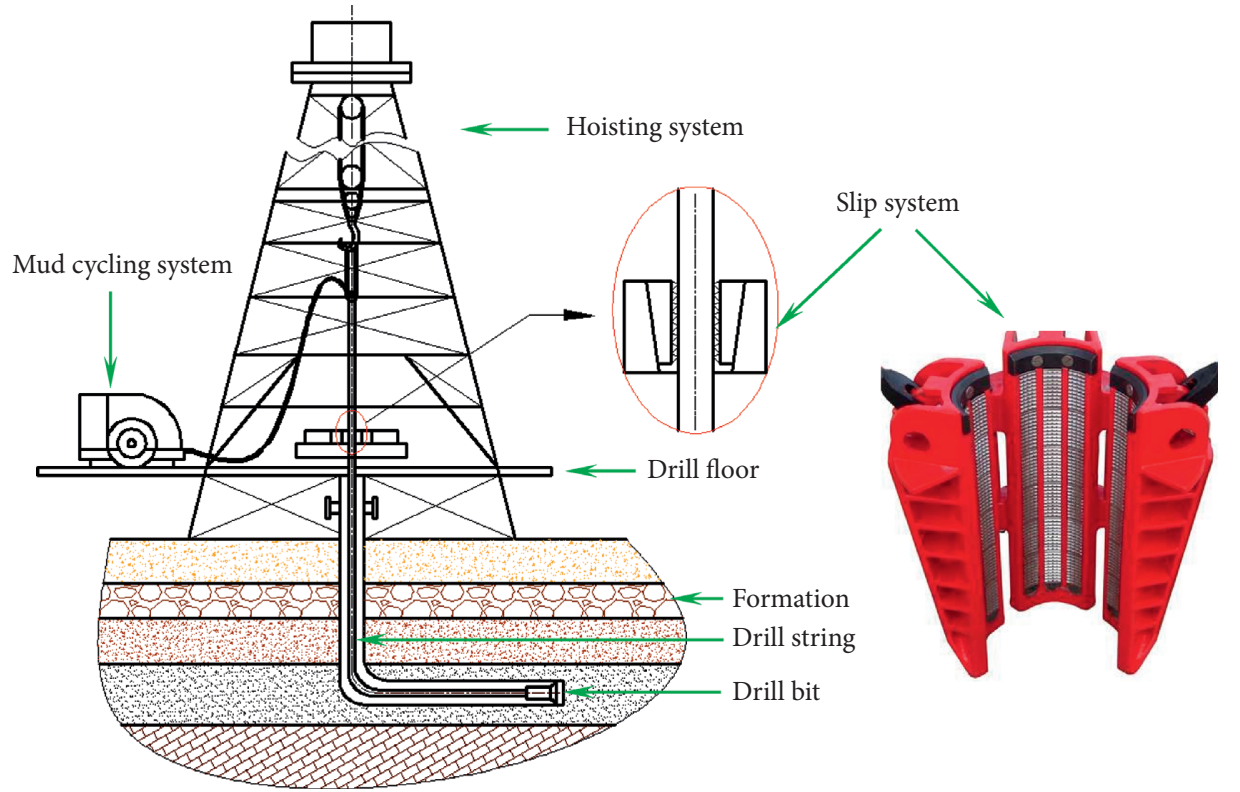

FIGURE 1: Schematic of a drilling system with a slip system located on the rotary table.

clamping the DP in this way causes irreversible damage to the outer surface of the DP as well as the slip inserts $[13,14]$, and the stress concentrations between the slip inserts and the DP can initiate fracture or fatigue, thereby causing the DP to fail in subsequent use and resulting in a serious drilling accident $[15,16]$. Figure 2 shows an example of a DP failure due to die marks. The greater the DP weight, the more severe the damage. Previous research has shown that the structure of the slip insert has a considerable impact on the DP damage in deep and ultra-deep well operation [17, 18]. Therefore, optimizing the structural parameters of the slip insert is very important to the petroleum industry.

The analysis of DP failure due to slip crushing dates back to the work by Reinhold and Spiri [19] in 1959, in which the mechanical behavior of the contact region between the DP and rotary slip was investigated. In their paper, the DP is considered to be subjected to a symmetric axial load in the slip contact area. By regarding the slip system as an immoveable wedge, the ratio of the transverse loading to the axial loading can be derived and the average radial pressure acting on the outer wall of the DP can be estimated. Knowing the radial pressure, the tangential stress at the inner wall of the DP can be estimated. In this way, a formula for calculating the crushing load $F_{\text {crush }}$ can be obtained by combining the axial stress and the tangential stress, namely,

$$
F_{\text {crush }}=F_{\text {yield }} \sqrt{\frac{2}{1+\left[1+\left(K d_{O} / 2 L\right)\right]^{2}+\left[\left(K d_{O} / 2 L\right)\right]^{2}}},
$$

with

$$
K=\frac{F_{T}}{F_{A}}=\frac{1-\mu_{\mathrm{BS}} \tan \alpha}{\mu_{\mathrm{BS}}+\tan \alpha},
$$

where $F_{\text {yield }}$ is the yield force of the DP, $K$ is known as the " $K$-factor," $d_{O}$ is the outer diameter of the DP, $L$ is the length of the contact region, $F_{T}$ is the tangential force, $F_{A}$ is the

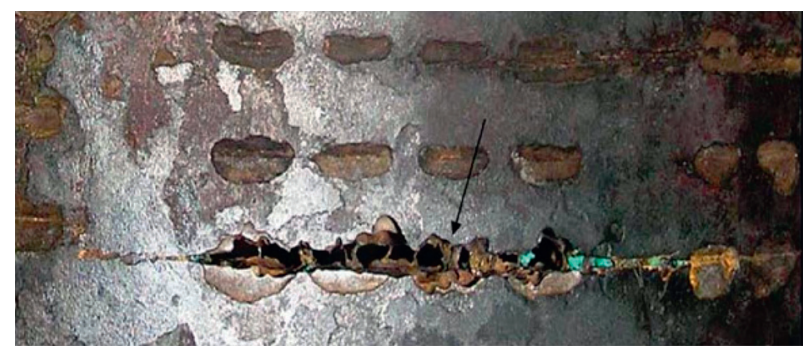

FIgURE 2: Example of drill-pipe (DP) failure due to die marks [16].

axial force, $\mu_{\mathrm{BS}}$ is the coefficient of friction between the slip body and the bowl, and $\alpha$ is the tapered angle of the slip body. Figure 3 shows the change laws of the $K$-factor with respect to friction coefficient $\mu_{\mathrm{BS}}$ and slip angle $\alpha$. As shown in Figure 3(a), the $K$-factor decreases with increasing the friction between the slip body and bowl, which means a small $K$-factor can be obtained by applying a high friction coefficient. It is reported in Figure 3(b) that the $K$-factor decreases with the increase of slip angle, meaning using a large slip angle can be helpful to obtain a small $K$-factor. However, relative sliding may appear due to high coefficient friction or high slip angle. For the drilling application, it must be emphasized that the slip angle is standardized by the American Petroleum Institute (API) to $9^{\circ} 27^{\prime} 45^{\prime \prime}$. Figure 4 shows the change laws of the crushing load with respect to $K$ factor and contact length.

The Reinhold-Spiri formula, e.g., equation (1), has been used to calculate both the crushing load of the DP and the radial forces exerted by the packers on the tubing [20]. Vreeland [21] carried out eight groups of tests on 5-in DPs and compared the test results with the predictions of equation (1), the test results agreeing satisfactorily with the theoretical ones. However, recent investigations of DP failure have indicated that using the Reinhold-Spiri formula to calculate the yield load of the DP is nonconservative [22] 


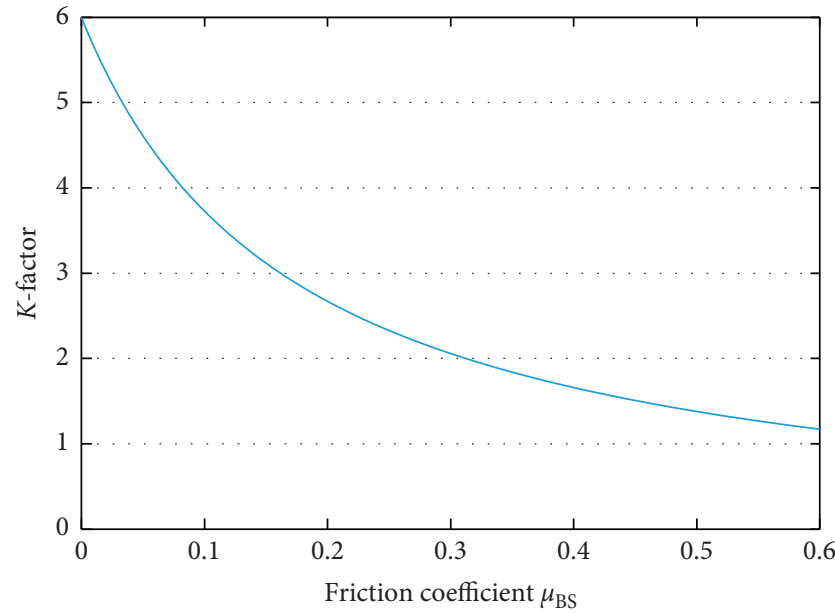

(a)

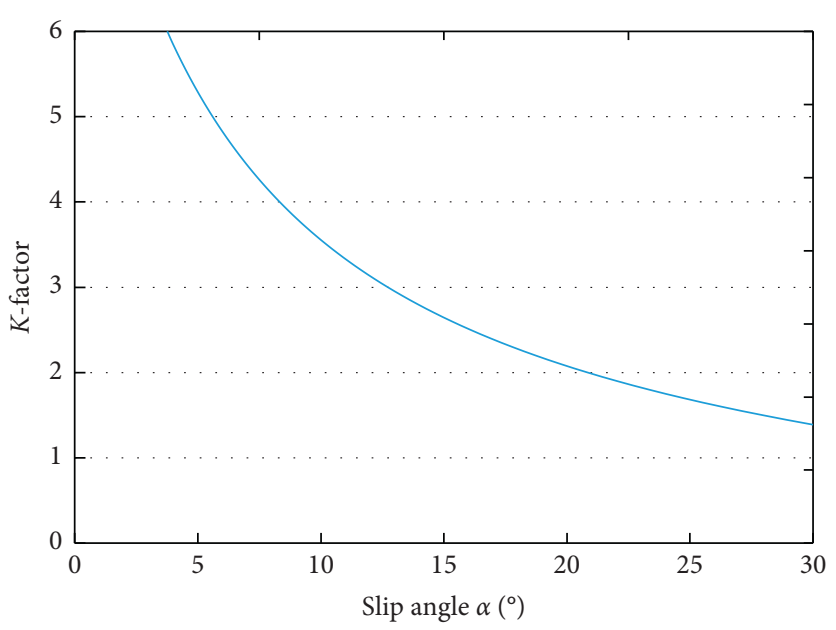

(b)

Figure 3: Change laws of the $K$-factor with respect to the friction coefficient and slip angle, (a) relationship between the $K$-factor and the friction coefficient and (b) relationship between the $K$-factor and slip angle.

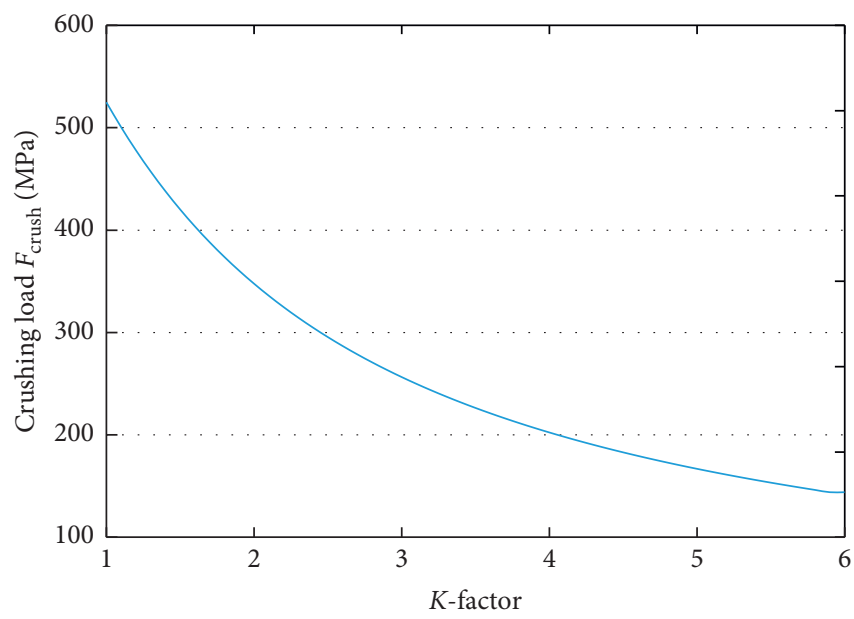

(a)

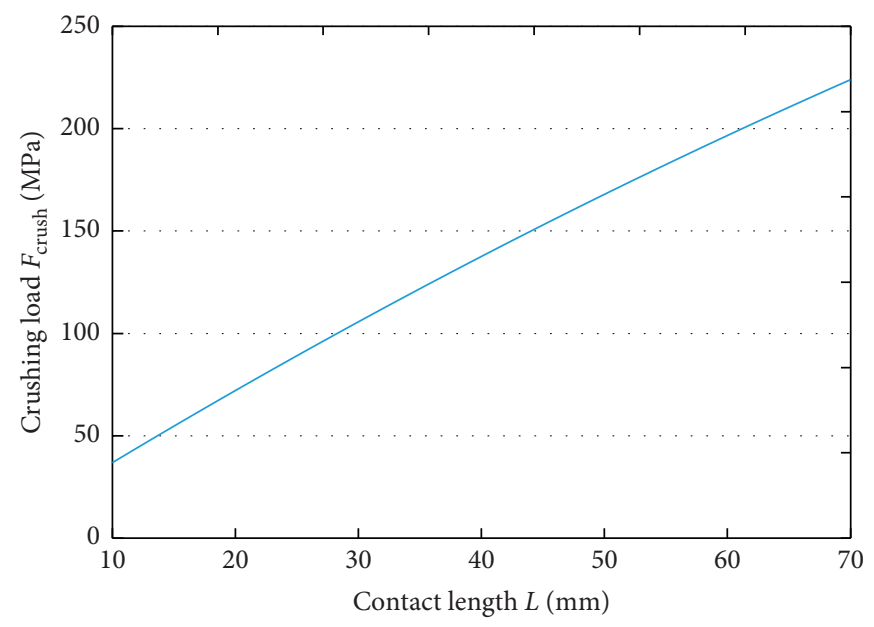

(b)

Figure 4: Change laws of the crushing load with respect to the $K$-factor and contact length, (a) relationship between the crushing load and the $K$-factor and (b) relationship between the crushing load and contact length.

because the yielding on the inner diameter of the DP initiates at values around $20 \%$ less than that predicted by the theoretical formula. Following the Reinhold-Spiri and Vreeland studies, work on slip crushing made little progress for more than two decades. Then, to reduce the probability of DP yielding, Hayatdavoudi [23] investigated the design of the slip insert, and the results indicated that the DP deformation near the top of the slip is smaller than that above the toe of the slip. Sathuvalli et al. [8] then considered all the available experimental data on slip crushing and from them obtained a modified equation for the slip crushing load; they also described the physical principle of the interaction between the slip and DP in more detail based on the Reinhold-Spiri analysis.

Looking at the results of the present literature survey in more detail, most of the identified publications were focused on the crushing force or handling limitation of the slip
$[24,25]$. The structure or geometry of the slip insert undoubtedly has a considerable influence on the mechanical behavior of the DP because permanent marks are produced on the pipe body [26, 27]. As a result, conducting researches on optimization of the slip insert is of great significance. In the investigations of pipes or pipelines, the finite element method (FEM) has been widely used, which presents an effective tool for mechanical analysis of pipes. Gadala et al. $[28,29]$ and $\mathrm{Ni}$ et al. [30] studied the influences of external corrosion (for example, electrochemical corrosion) and welding performance on the pipe stress. In the studies by Qian [31-33], FEM was used to assess the failure due to semielliptical surface cracks in the pipes. Zhao et al. [34] studied the welded clad pipe with a circumferential partthrough external surface crack subjected to bending moment by using $3 \mathrm{D}$ elastic-perfectly plastic FEM. Based on the FEM, Tang et al. [35] developed a finite element (FE) model to 
study how the slip-insert geometry affects the mechanical behavior of the DP, but little other research related to optimizing the slip insert can be found. The die marks are likely to give rise to problems related to fracture and fatigue. For a specific slip system and DP, engineers are likely to be interested in how to reduce the stress acting on the DP, thereby limiting the damage done to the DP and thus extending its lifetime.

In the present paper, we study the parameter optimization of a new type of slip insert (wherein multiple ranks of teeth are arranged) that differs from the one presented in our previous work [35]. In Section 2, we develop an FE model, and we present and discuss the simulation results in Section 3. Finally, we draw our conclusions in Section 4.

\section{Slip-Drill-Pipe Model}

2.1. Physical and Mechanical Models. To explore how the slip-insert parameters affect the slip insert and the DP damage, we must first establish the corresponding physical and mechanical models. Two types of slip inserts are commonly used in field applications, one in which there is only one rank of teeth and the other in which there are multiple ranks of teeth (see Figure 5). Figure 6 shows a schematic of the slip-DP interaction. The DP is pulled axially under the action of its weight, and the friction force between the slip and the DP causes the slip to slide downward. Because the outer surface of the slip body is a tapered wedge, this movement of the slip generates a radial force between the DP and the slip insert that embeds the slip insert into the DP and thus clamps the DP. Herein, a 5-in DP that is commonly used in the oil industry is adopted as the basis of these models, in which the inner diameter of the DP is $108.6 \mathrm{~mm}$. The DP is subjected to an axisymmetric force in the contact area, and the axial force on the DP is regarded as the pipe weight applied to the bottom of the DP. The outer surface of the slip and the inner surface of the slip bowl are tapered with an angle of $9^{\circ} 27^{\prime} 45^{\prime \prime}$ according to the API standard.

2.2. FE Model of Slip-DP System. Based on the physical and mechanical models, the FE model shown in Figure 7 is established with the ABAQUS program [36]. For the slip system studied herein, the geometry of the slip insert is shown in Figure 7. In a common slip system, 54 slip inserts are arranged in six rows and nine ranks. However, in the present FE model, only one row of slip inserts is used, with the slip inserts being distributed circumferentially around the DP. To match the actual working conditions, a preload is applied on the upper end face of each slip before the drill pipe weight loading on the DP so that the slip inserts can clamp the DP firmly. The weight of the DP considered herein is 180 tons; however, because only one of the six rows of slip inserts is modeled, the load acting on the lower end of the DP is regarded as being only 30 tons. The DP generates an axial load under the action of gravity, and in the present model, the equivalent pressure loaded on the lower end of the DP was used to represent the axial load. Based on the outer and inner diameters of the DP, this equivalent pressure is determined as $88.112 \mathrm{MPa}$.

Friction is one of the most important factors affecting the performance of the slip-DP system. Herein, the interaction between any two surfaces in contact is surface-to-surface contact based on penalty contact. In the model, the coefficient of friction between the slip and the slip bowl is 0.1 and that between the DP and the slip is $0.3[6,8]$.

In addition, two steps are used to determine the boundary conditions and the loading procedures. In the first step, a preload is exerted to establish contact between (i) the bowl and the slip body and (ii) the slip insert and the DP; a pressure of $1 \mathrm{MPa}$ is applied on the upper end of each slip insert. In the second step, the load acting on the slip inserts is removed and an axial load is applied to the DP as determined by its weight. The values of the various parameters in the model are listed in Table 1.

\section{Numerical Simulations}

The slip insert is the part that is in direct contact with the DP, and its structure has a substantial influence on not only its own mechanical properties but also those of the DP. To obtain an optimal combination of slip-insert structural parameters, herein we analyze the four, namely, (i) the frontrake angle (FRA), (ii) the back-rake angle (BRA), (iii) the chamfer, and (iv) the tooth height. To determine values for these parameters, we conduct orthogonal analyses based on several versions of the FE model.

3.1. Analysis of Rake Angles. The rake angles must lie in reasonable ranges because (i) a large FRA and a large BRA could cause the DP to fracture and the slip insert to fail prematurely, while (ii) a small FRA and a small BRA could cause the slip not to clamp the DP and the DP to slip off the slip system. Given the present research approach and rakeangle requirements and according to the orthogonal experimental design method, herein we analyze 42 combinations of FRA and BRA from seven FRAs and six BRAs. For this purpose, the tooth height is determined as $2 \mathrm{~mm}$ and the chamfer is ignored.

As shown in Figure 8, the maximum Mises stress on the DP generally shows a gradual decrease trend, and after the FRA is greater than $70^{\circ}$, the trend of stress reduction tends to be gentle. In Figure 9, the maximum Mises stress on the slip insert is plotted as a function of the FRA for each value of the BRA. In general, the stress on the slip insert is large with both small and large FRA. However, the stress on the slip insert is small when the FRA is relatively small, i.e., $65^{\circ}, 70^{\circ}$, and $75^{\circ}$.

Considering the results shown in Figures 8 and 9, the combination of an FRA of $70^{\circ}$ and a BRA of $30^{\circ}$ is regarded as the optimized parameter group of the slip insert. With this combination, the stress contours of the slip-DP system are shown in Figure 10. With a BRA of $30^{\circ}$, the stress contours of the DP and slip insert with different FRAs are shown in Figures 11 and 12. For a certain part in the contact area of the $\mathrm{DP}$, it is interesting that the stress of the inner surface is higher than that of the outer surface, which means the crush 


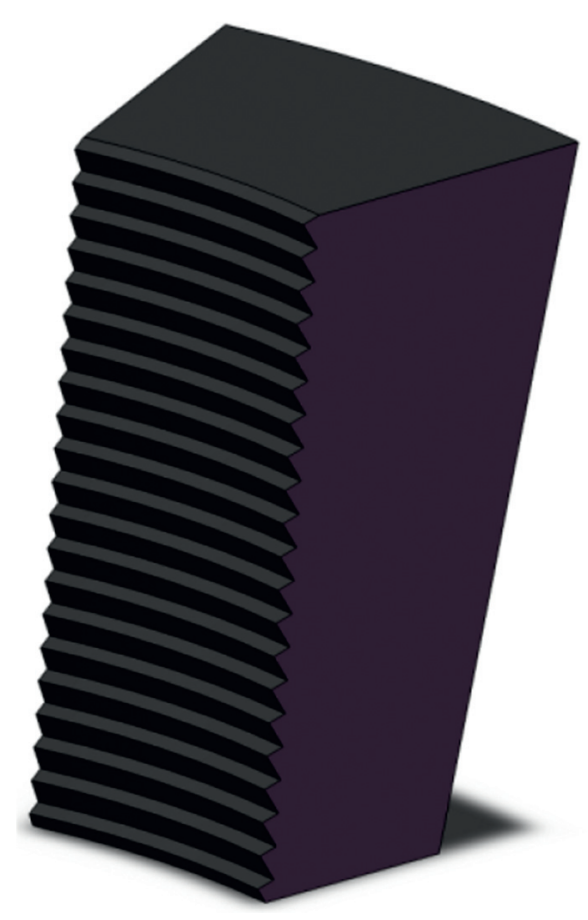

(a)

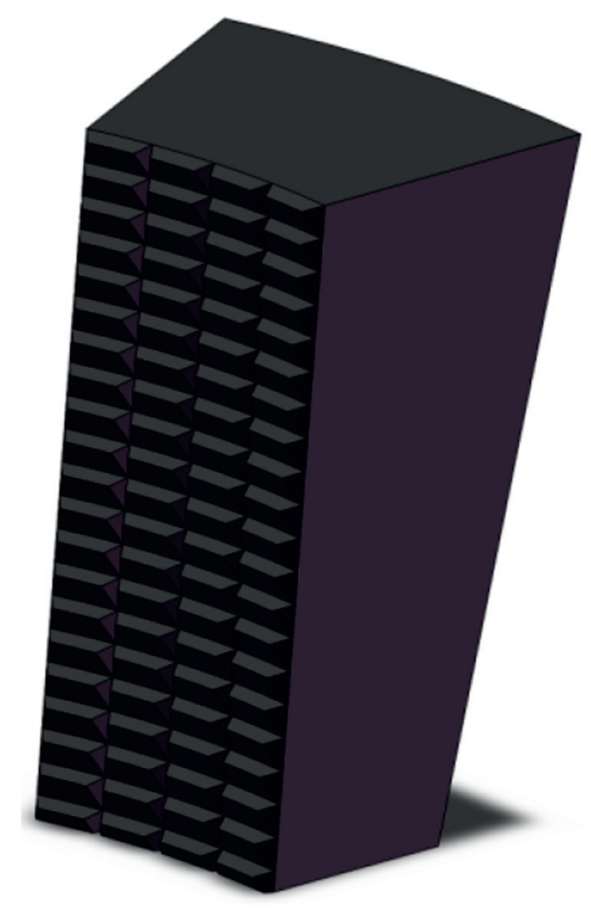

(b)

FIGURE 5: Two typical types of slip inserts, (a) slip with only one rank of teeth and (b) slip with four ranks of teeth.

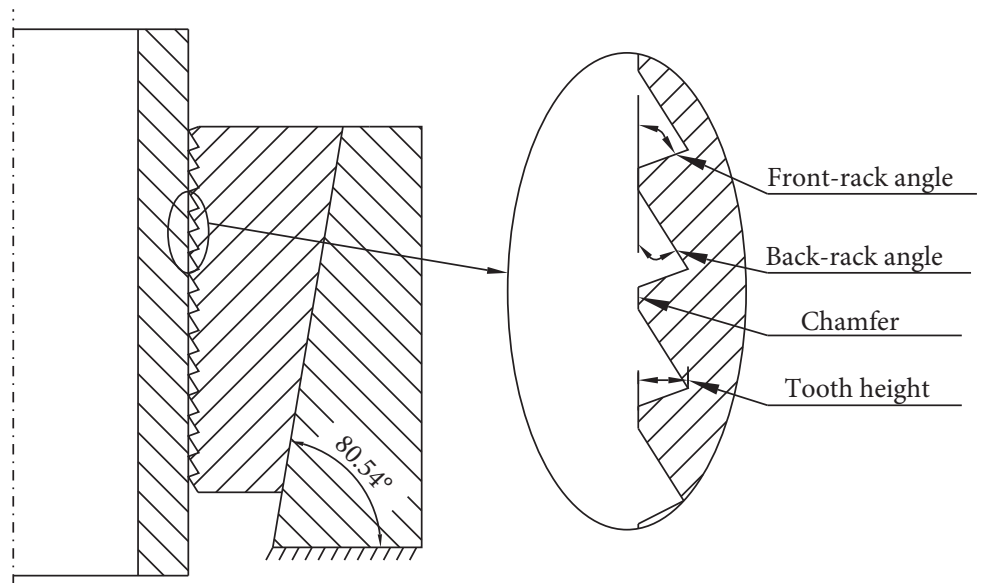

(a)

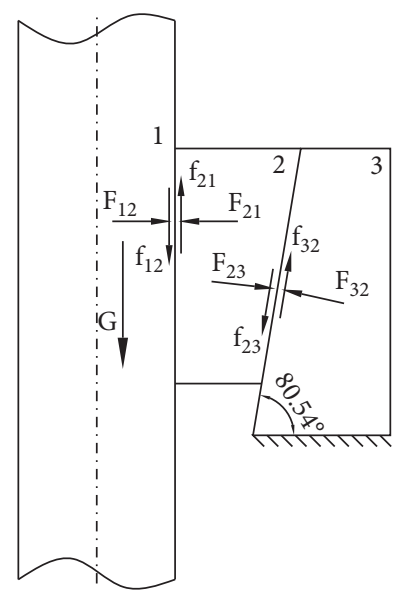

(b)

Figure 6: Schematic of the slip-DP system, (a) longitudinal profile of the system, showing a DP, a slip, and a rotary table which are included in the system, and (b) the force diagram of the system.

phenomenon of the DP will first appear on its inner surface. Once the stress exceeds the yields value of the material, plastic deformation or plastic strain appears. Figure 13 shows the equivalent plastic strain of the slip inserts, where the contours correspond to the stress distributions shown in Figure 12. It can be seen from the deformed stress contours that when the FRA is $70^{\circ}$ and the BRA is $30^{\circ}$, the large stress distribution on the inner wall of the DP is relatively uniform and the slip inserts with large plastic strain are less. Therefore, the combination of an FRA of $70^{\circ}$ and a BRA of $30^{\circ}$ is reasonable.

The stress contours of the DP with the combination of an FRA of $70^{\circ}$ and a BRA of $30^{\circ}$ are shown in Figure 14 . The maximum Mises stress on the DP occurs on its inner surface and decays rapidly away from that surface. The stress distribution on the DP inner surface is similar to that on the slip insert around the DP. However, the maximum Mises stresses on the inner surface occur not at the angles at which the 


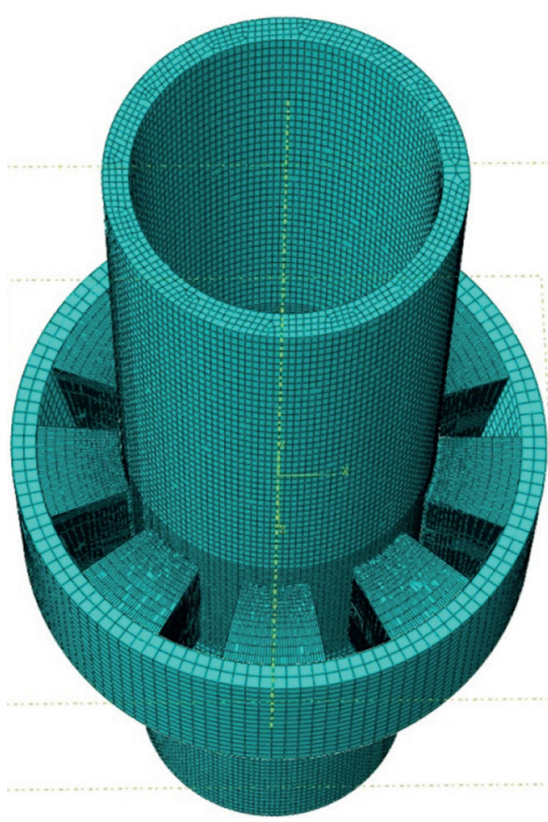

(a)

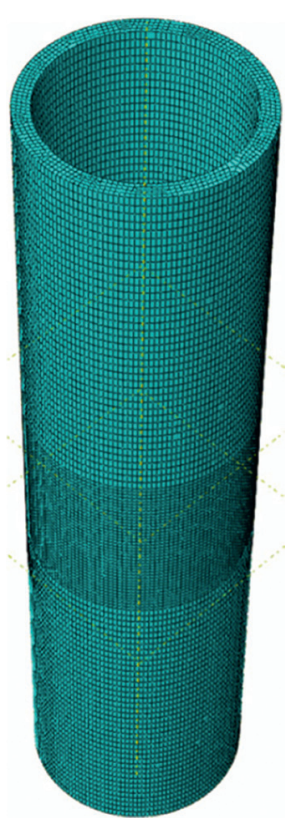

(b)

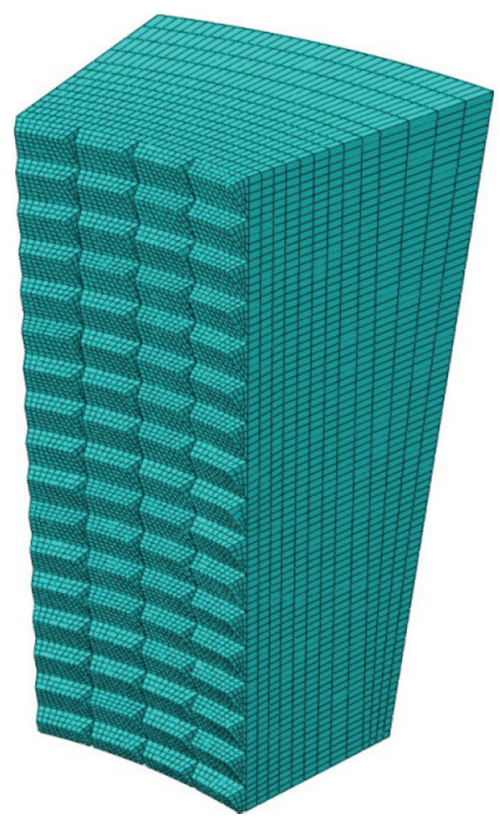

(c)

FIGURE 7: Finite element (FE) model of the slip-DP system: (a) a meshed global system includes a DP, a slip, and a rotary table, (b) the meshed DP, and (c) one of the meshed slips.

TABLE 1: Parameters and corresponding values of the two materials used in the FE model.

\begin{tabular}{lc}
\hline Parameter (for 20CrMnMo, the material of the drill pipe and slip bowl) & Value \\
\hline Density & $7,870 \mathrm{~kg} / \mathrm{m}^{3}$ \\
Poisson's ratio & 0.254 \\
Young's modulus & $207 \mathrm{GPa}$ \\
Yield strength & $885 \mathrm{MPa}$ \\
Tensile strength & $1,185 \mathrm{MPa}$ \\
\hline Parameter (for 20CrMnTi, the material of the slip) & Value \\
Density & $7,870 \mathrm{~kg} / \mathrm{m}^{3}$ \\
Poisson's ratio & 0.254 \\
Young's modulus & $207 \mathrm{GPa}$ \\
Yield strength & $835 \mathrm{MPa}$ \\
Tensile strength & $1,080 \mathrm{MPa}$ \\
\hline
\end{tabular}

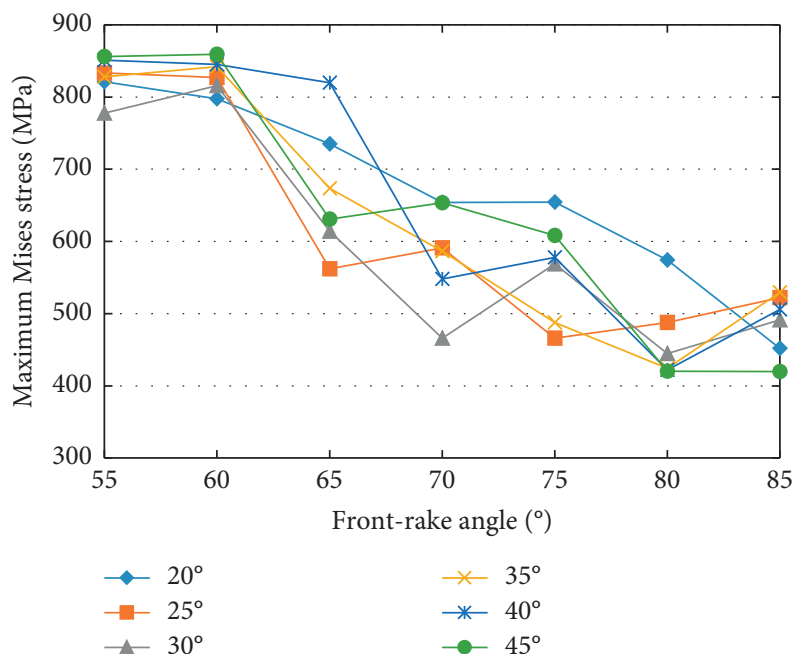

Figure 8: Maximum Mises stress on the DP for different values of back-rake angle (BRA).

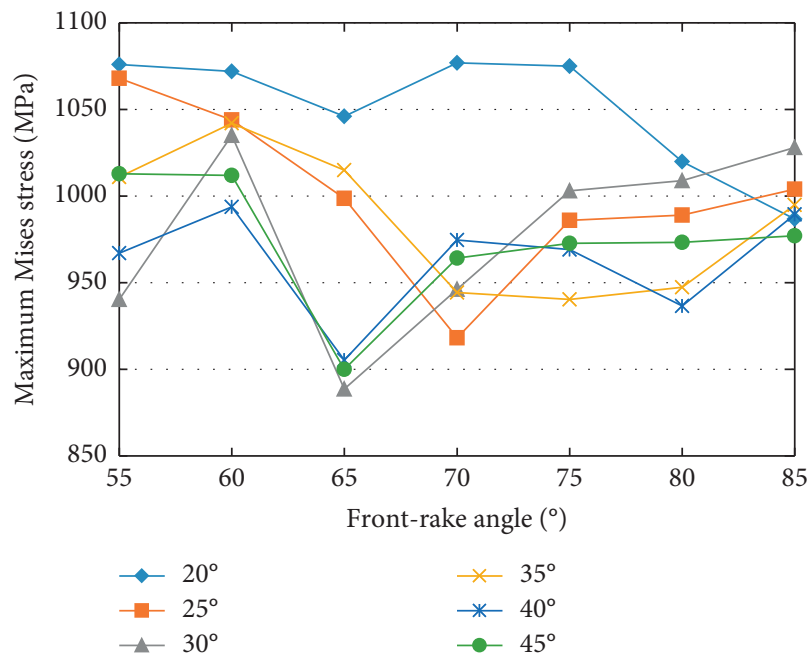

Figure 9: Maximum Mises stress on the slip insert for different values of BRA. 


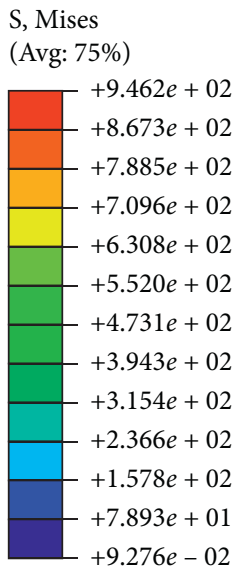

S, Mises

(Avg: $75 \%)$

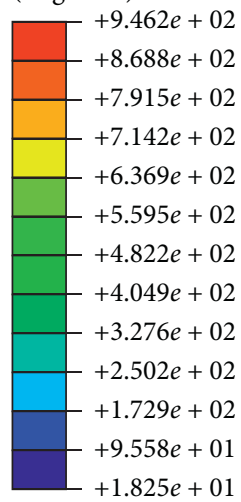

$+1.825 e+01$

(a)

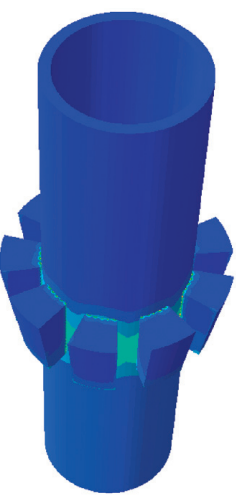

(a)
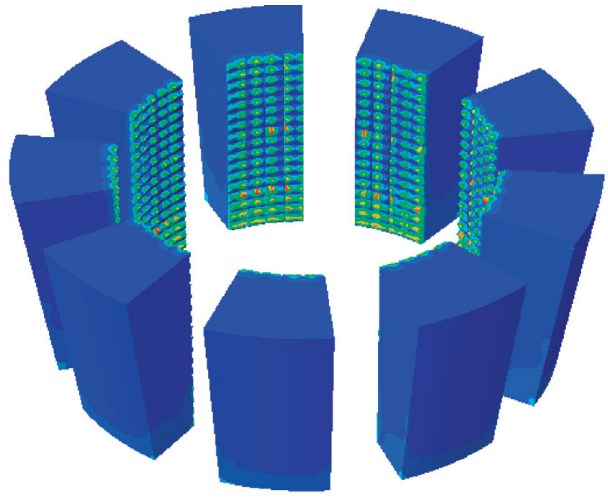

(b)

FIGURE 10: Stress contours with a front-rake angle (FRA) of $70^{\circ}$ and a BRA of $30^{\circ}$ : (a) slip-insert-DP system; (b) slip insert.

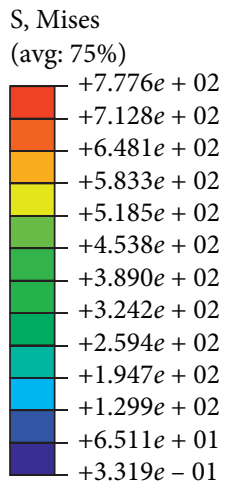

S, Mises (avg: 75\%)

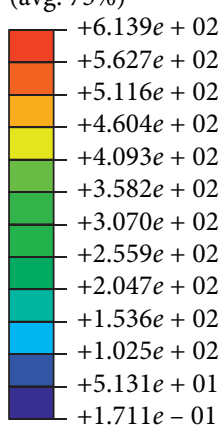

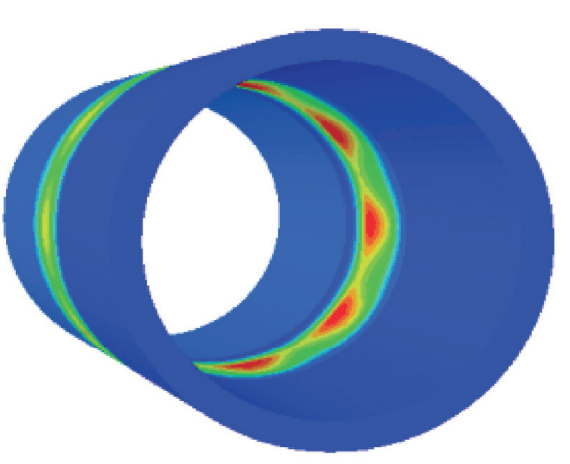

(a)

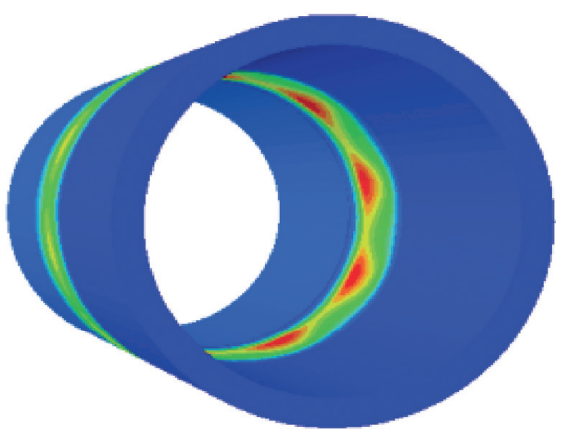

(c)
S, Mises

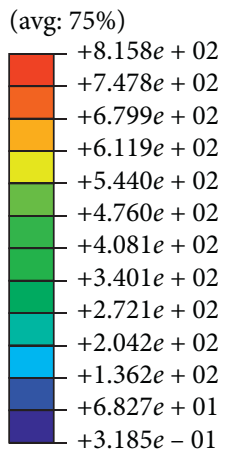

S, Mises

(avg: $75 \%$ )

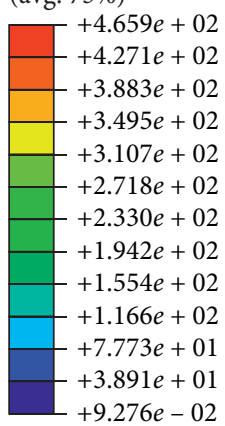

$+9.276 e-02$

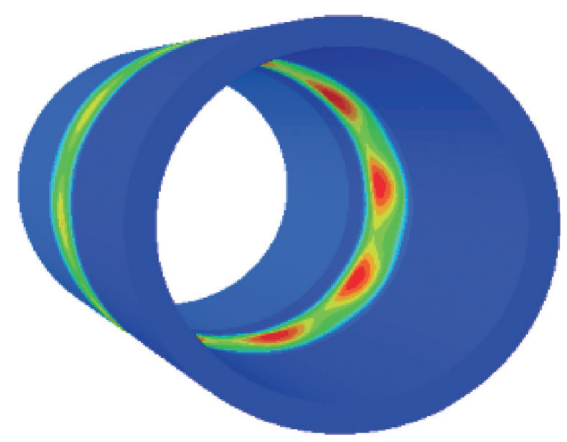

(b)

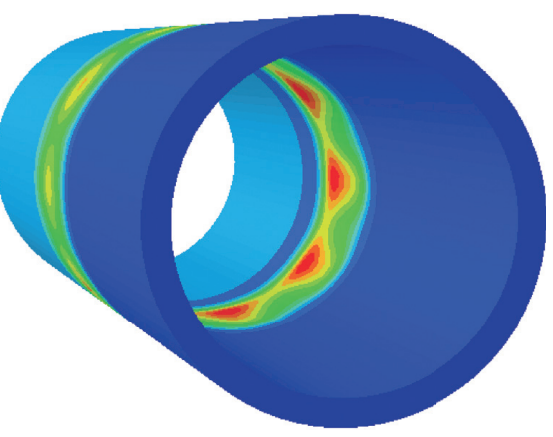

(d)

Figure 11: Continued. 


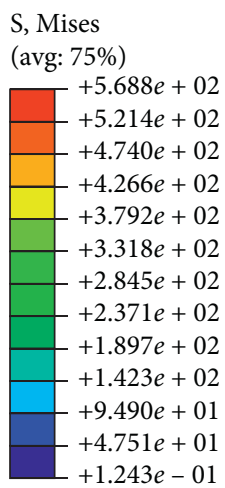

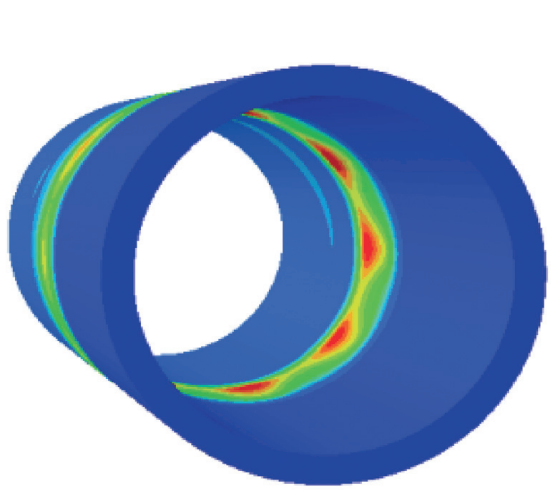

(e)
S, Mises

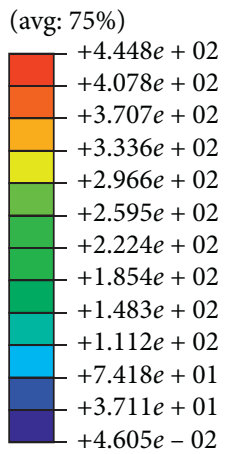

$+4.605 e-02$

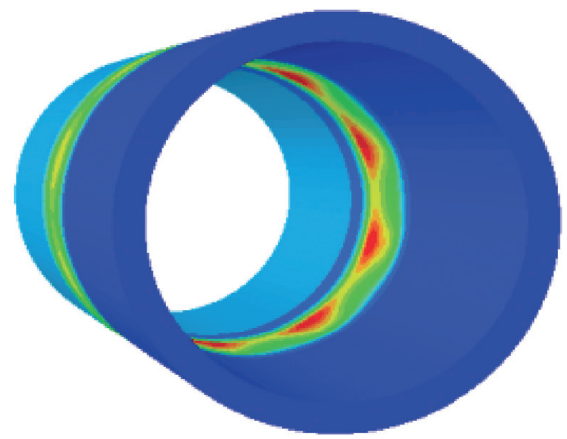

(f)
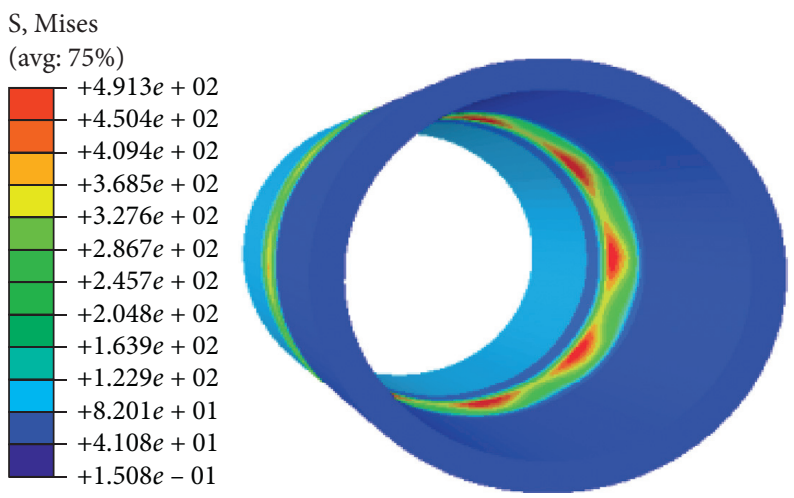

(g)

FIGURE 11: Stress distribution of the DP (a)-(g) for different FRAs (55-85 in steps of $5^{\circ}$, respectively), where the BRA is of $30^{\circ}$ in all models.

S, Mises

(avg: 75\%)

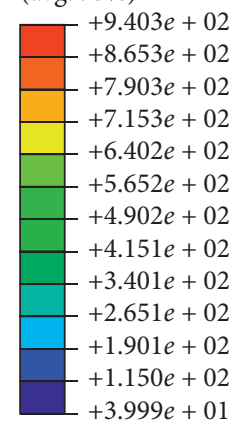

S, Mises

(avg: 75\%)

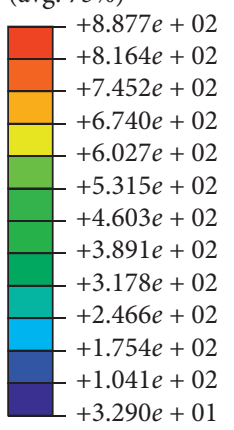

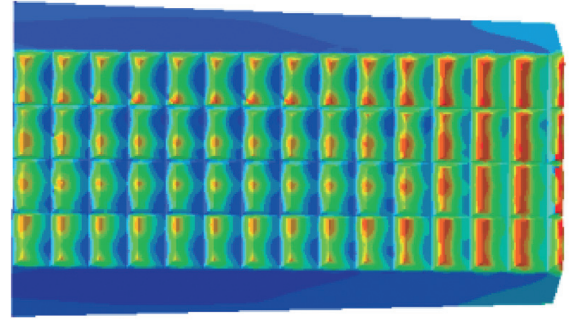

(a)

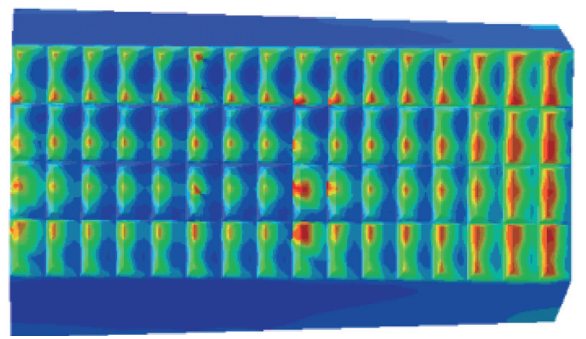

(c)
S, Mises

(avg: 75\%)
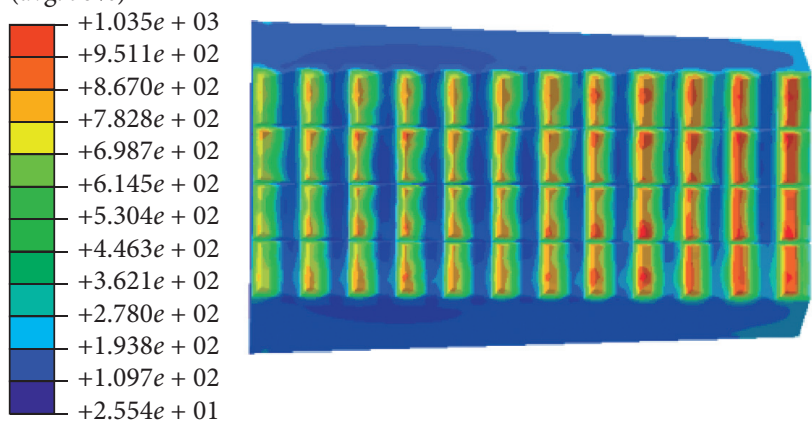

(b)

S, Mises

(avg: 75\%)
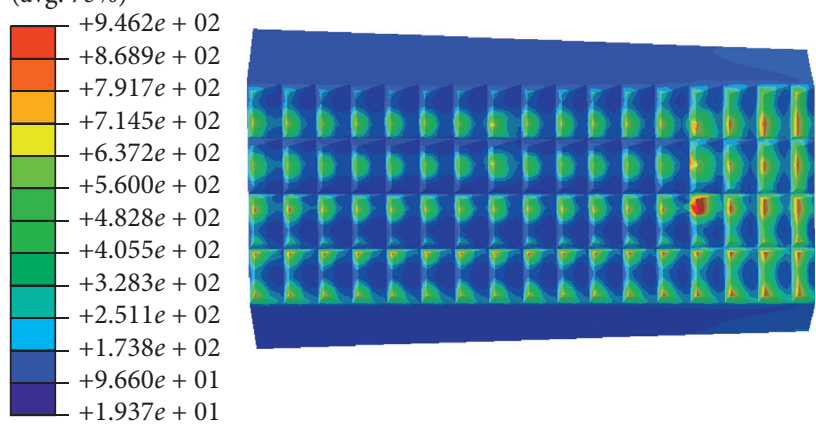

(d)

Figure 12: Continued. 


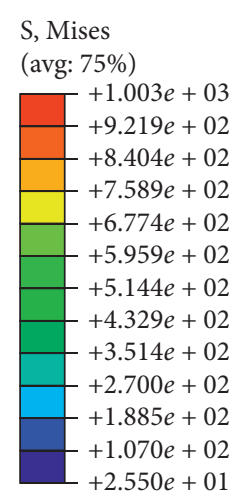

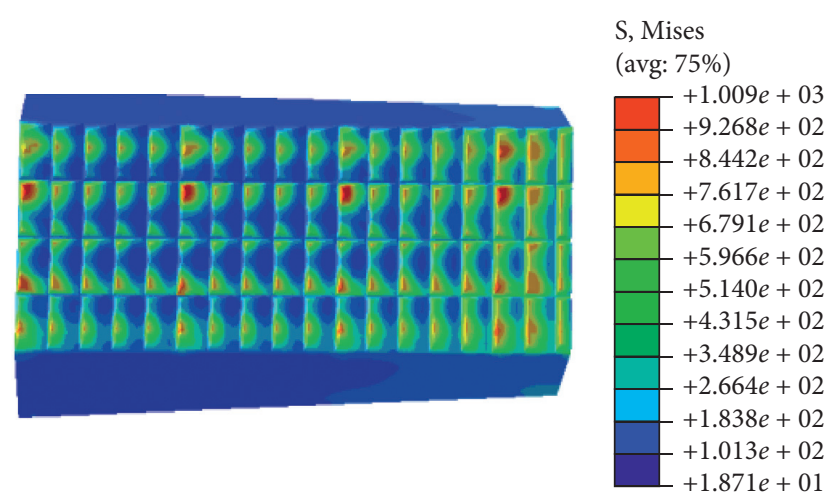

(e)

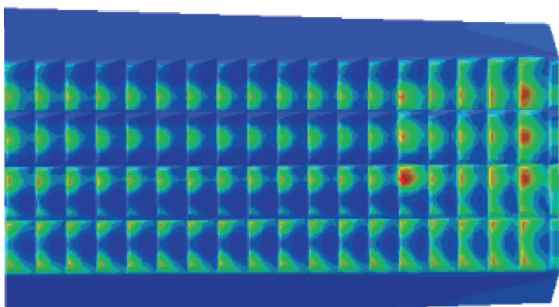

(f)
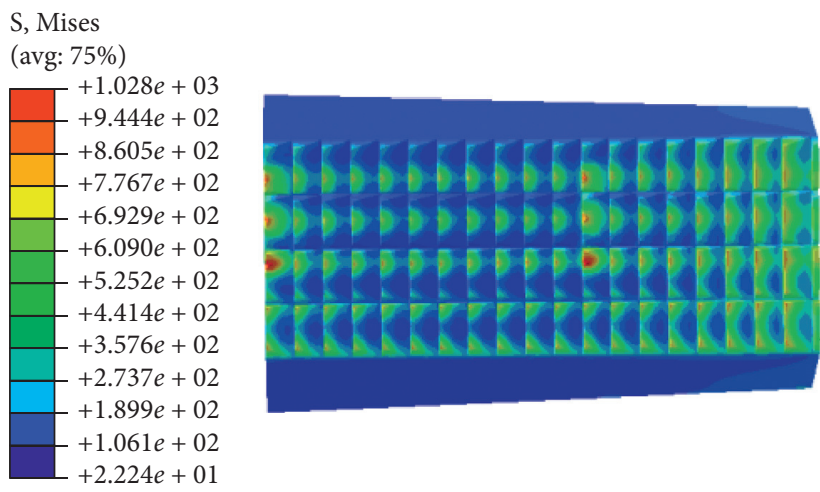

(g)

FIgURE 12: Stress distribution of the slip insert (a)-(g) for different FRAs (55-85 in steps of $5^{\circ}$, respectively), where the BRA is of $30^{\circ}$ in all models.

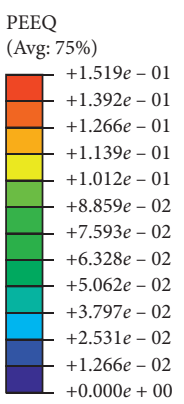

PEEQ

(Avg: 75\%)
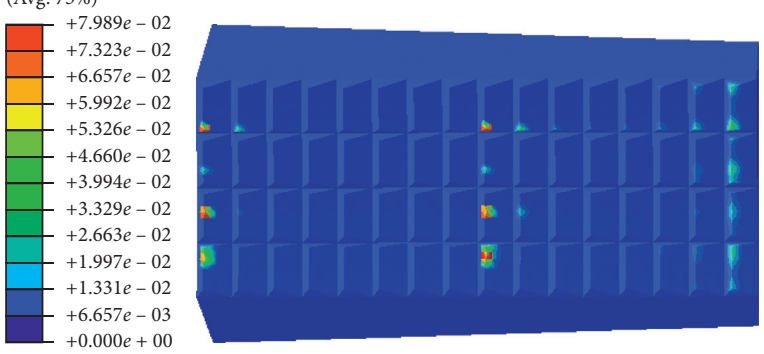

(c)

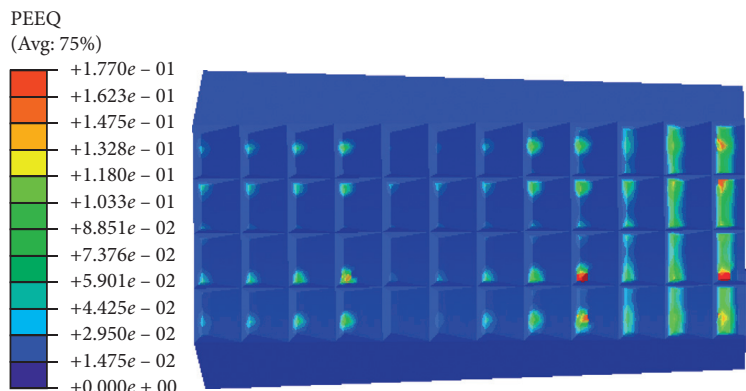

(b)

PEEQ (avg: 75\%)

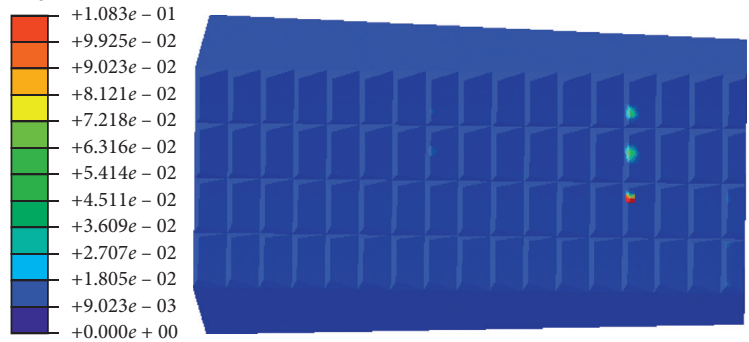

(d)

Figure 13: Continued. 


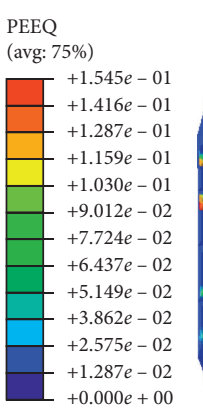

$+0.000 e+00$

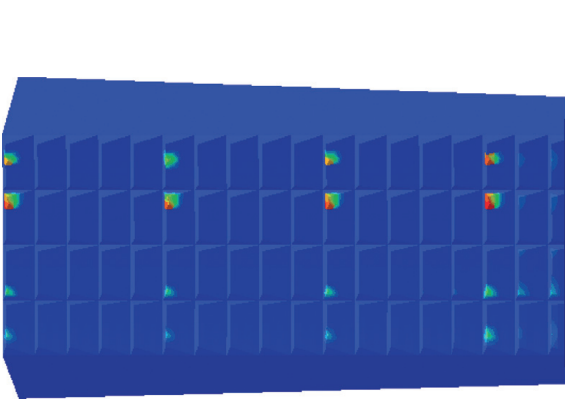

(e)
PEEQ

(avg: $75 \%$ )

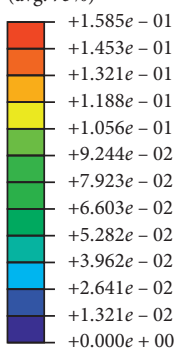

$+0.000 e+00$

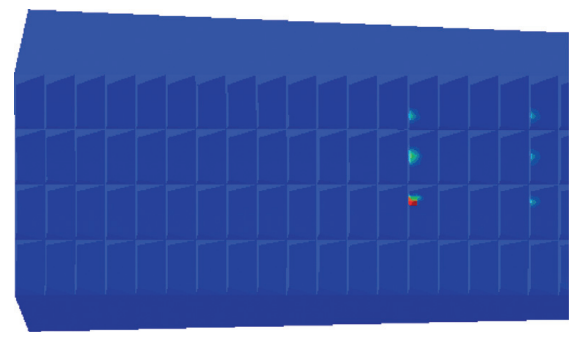

(f)

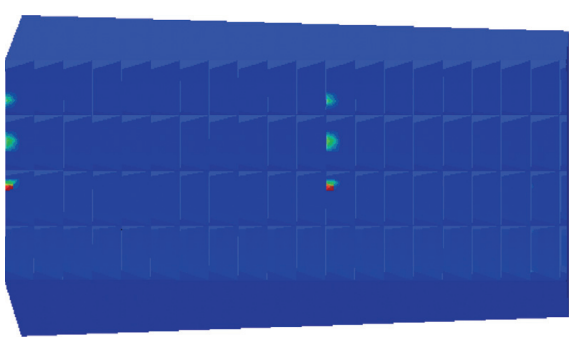

(g)

FIGURE 13: Equivalent plastic strain of the slip insert (a)-(g) for different FRAs (55-85 in steps of $5^{\circ}$, respectively), which are corresponding to the slip inserts presented in Figure 10, where the BRA is of $30^{\circ}$ in all models.

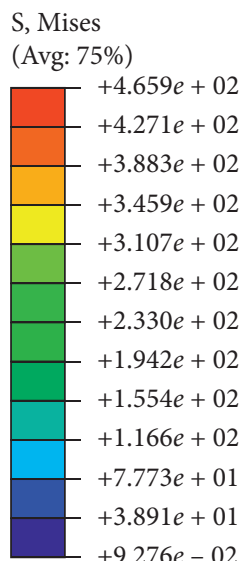

$+9.276 e-02$

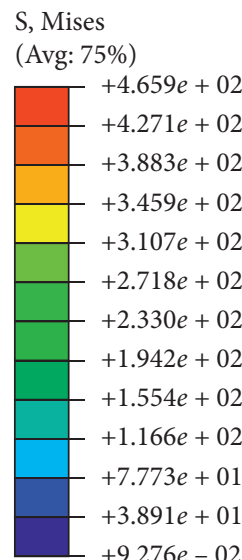

(a)

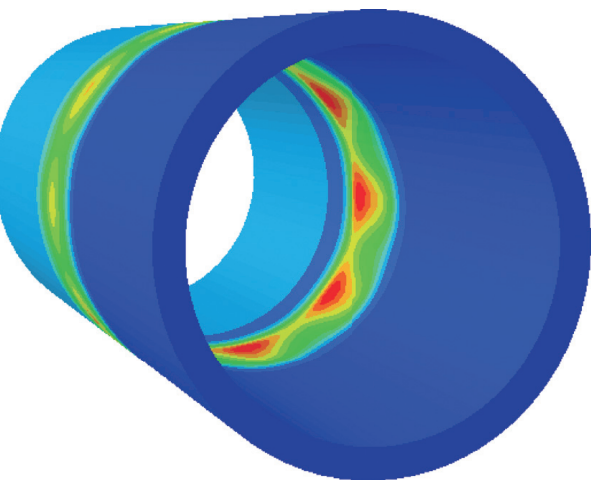

FIGURE 14: Stress contours of the DP: (a) general view; (b) half-sectional view.

teeth bite the DP but instead in the angular gaps between the slip teeth. In each simulation case, the maximum Mises stress appears on the inner wall of the cylinder while the radial pressure acts on the outer surface of the cylinder, which is consistent with the findings of theoretical analysis using the Lamé equation [37]. Consequently, plastic deformation is likely to occur on the inner surface when the pipe is extremely heavy, and this could be why the inner diameter of the DP reduces at the slip contact region when a long drill sting is used.
3.2. Analysis of Tooth Height. According to engineering practice regarding slip inserts, a large tooth height means fewer teeth and thus an excessively large radial force on each tooth. By contrast, a small tooth height means more teeth in the slip insert, but now the slip may be unable to clamp the DP because of the sludge on the latter. Therefore, choosing the correct tooth height is vital for ensuring the performance of the slip insert. Herein, several models are developed to study how the tooth height influences the mechanical behavior of both the DP and the 
S, Mises

(avg: $75 \%)$

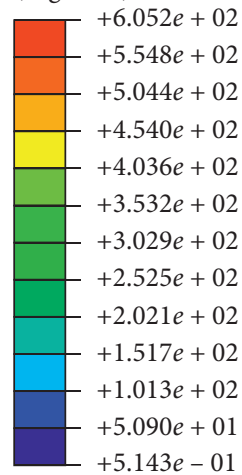

S, Mises

(avg: $75 \%)$

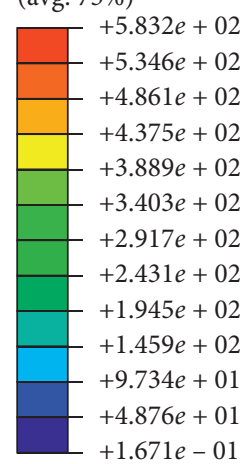

S, Mises

(avg: 75\%)

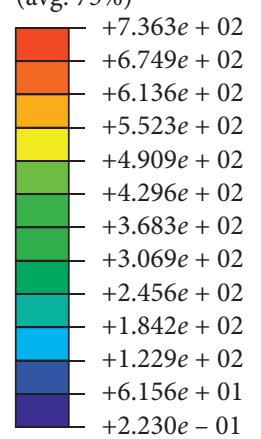

$+2.230 e-01$

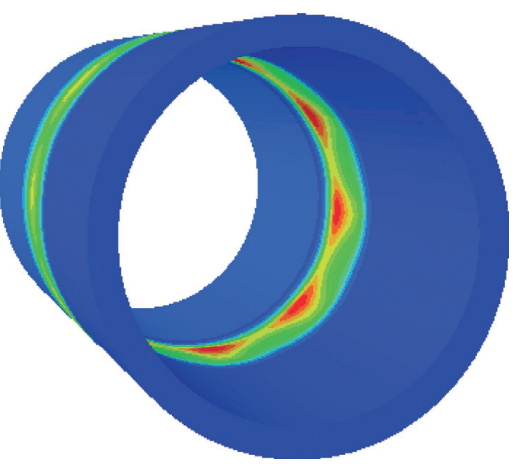

(a)

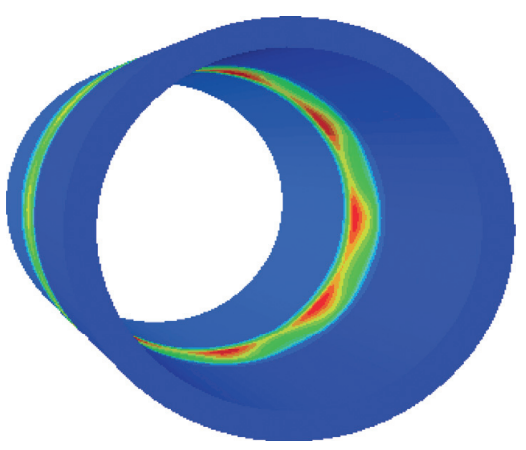

(c)

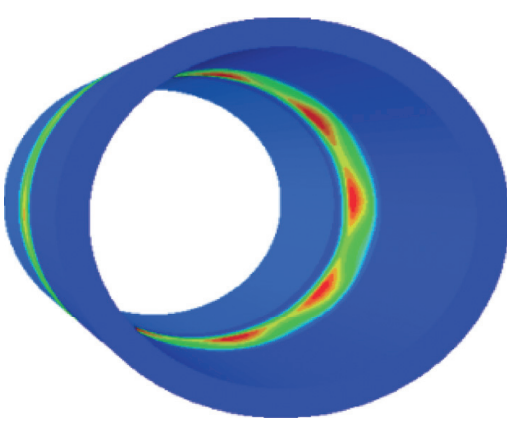

(e)
S, Mises

(avg: 75\%)

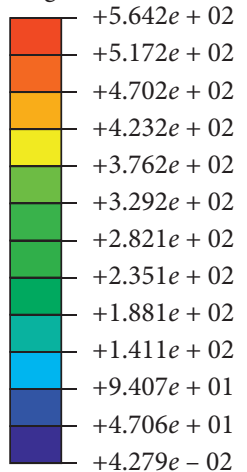

S, Mises

(avg: 75\%)

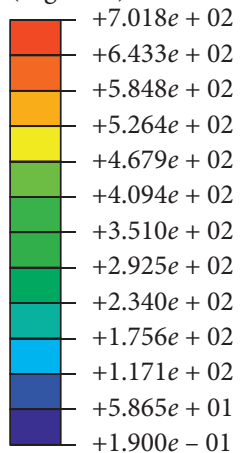

S, Mises

(avg: 75\%)

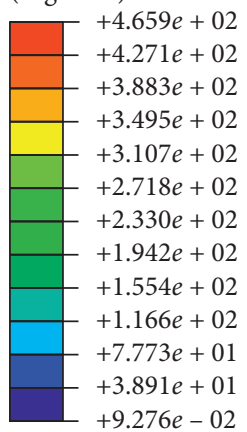

$+9.276 e-02$

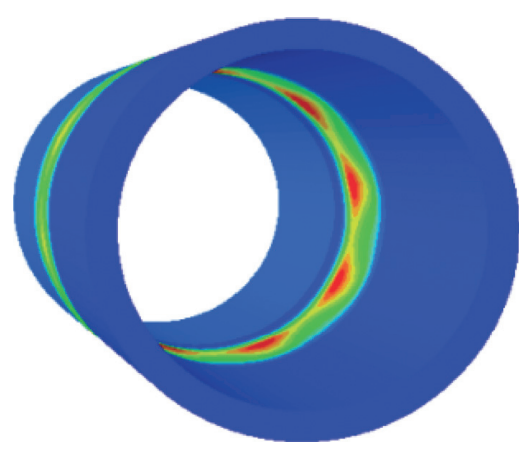

(d)

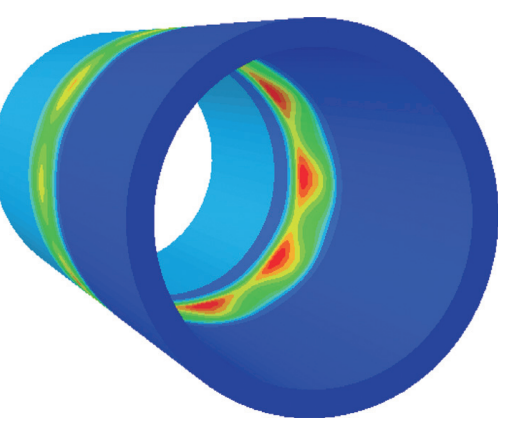

(f)

S, Mises

(avg: 75\%)
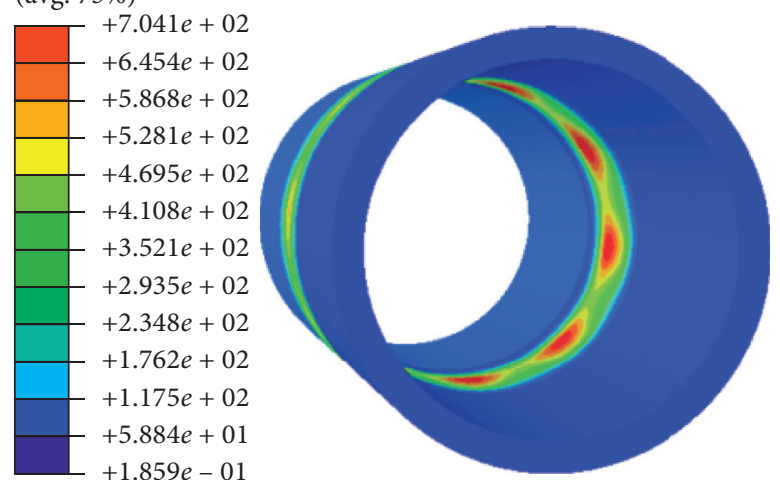

(g)

Figure 15: Stress contours of the DP (a)-(g) with different tooth heights ( $1 \mathrm{~mm}$ to $2.2 \mathrm{~mm}$ in steps of $0.2 \mathrm{~mm}$ ). 
S, Mises (avg: 75\%)
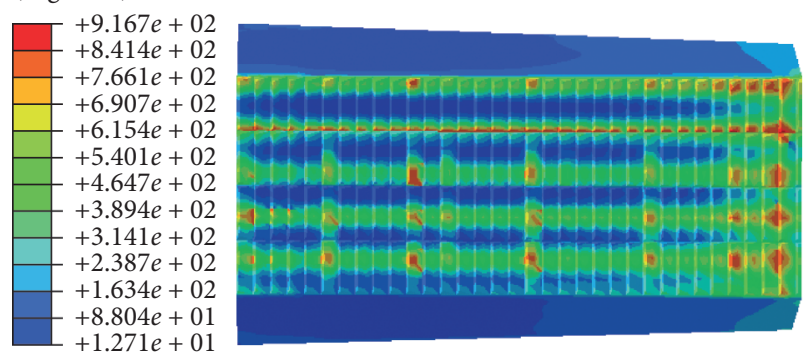

(a)

S, Mises (avg: 75\%)
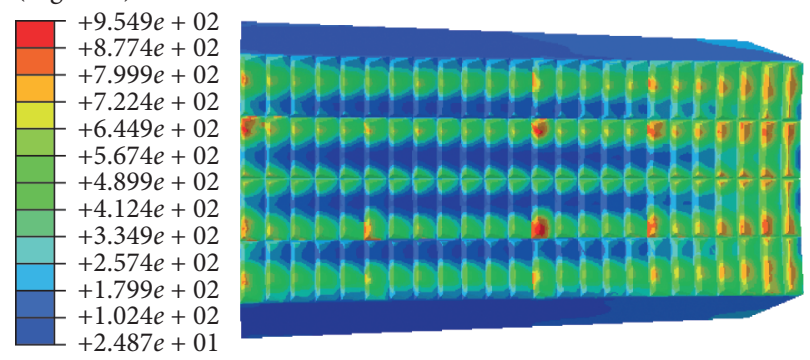

(c)

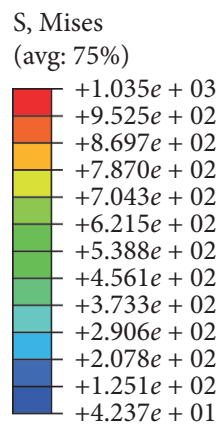

S, Mises

(avg: 75\%)

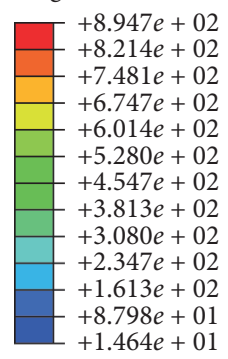

S, Mises (avg: 75\%)

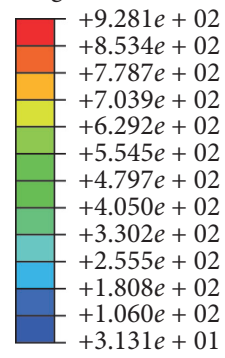

, Mises

(avg: 75\%)

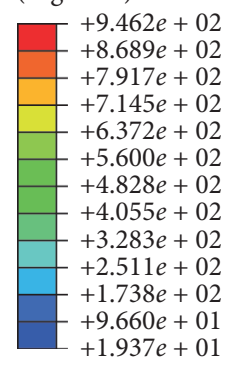

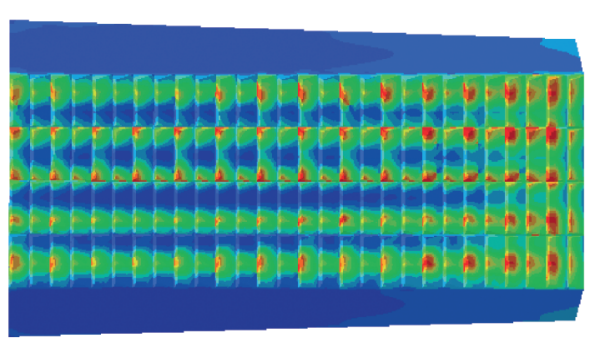

(b)

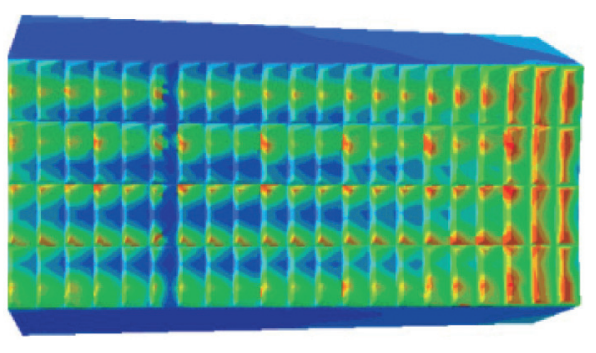

(d)

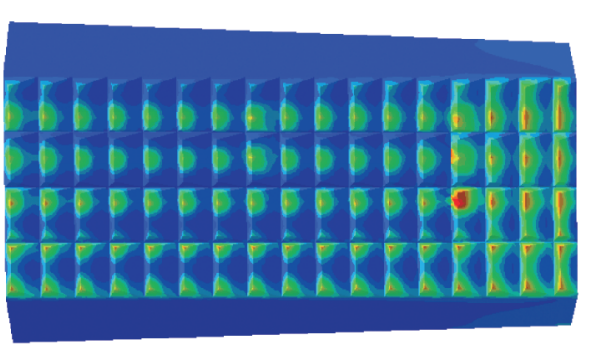

(f)

(e)

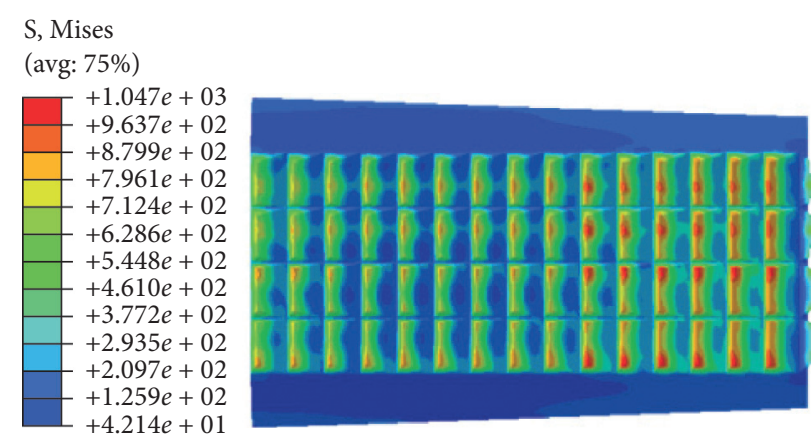

(g)

Figure 16: Stress contours of the slip insert (a)-(g) with different tooth heights ( $1 \mathrm{~mm}$ to $2.2 \mathrm{~mm}$ in steps of $0.2 \mathrm{~mm}$ ).

slip insert, for which an FRA of $70^{\circ}$ and a BRA of $30^{\circ}$ are selected. The stress contours of the DP and slip insert are shown in Figures 15 and 16, respectively. Being similar to the cases presented above, the stress of the inner surface of the DP is higher than that of the outer surface. For the contact section of the DP, the stress does not exceed the yields value of the material and thus plastic deformation does not appear. However, plastic deformation occurs on the slip inserts. Figure 17 shows the equivalent plastic strain contours of the slip inserts, corresponding to the strain contours of the stress contours presented in Figure 16. 
PEEQ

(avg: 75\%)
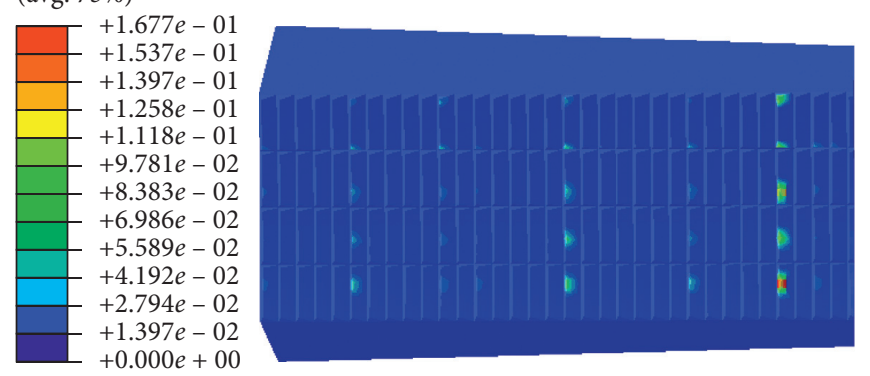

(a)

PEEQ

(avg: 75\%)
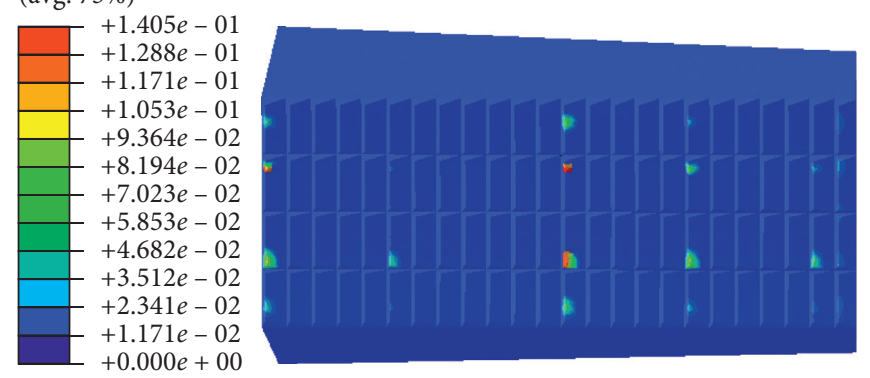

(c)

PEEQ

(avg: 75\%)
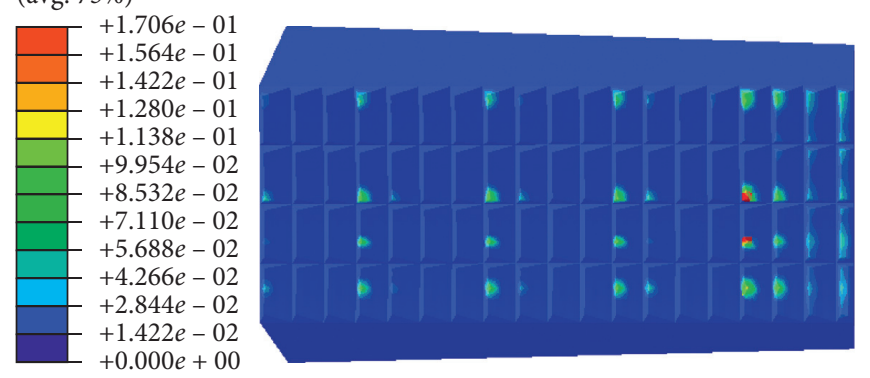

(e)

PEEQ

(avg: $75 \%$ )

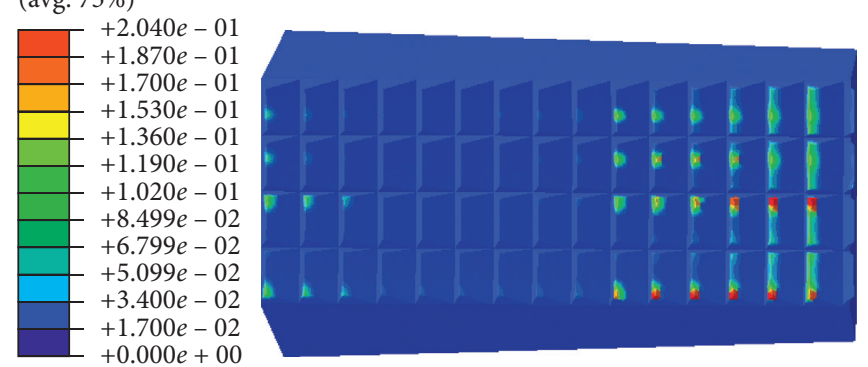

(g)
PEEQ

(avg: 75\%)

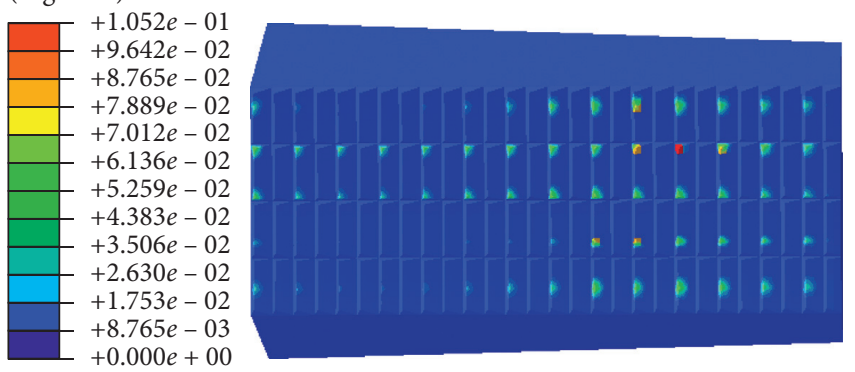

(b)

PEEQ

(avg: 75\%)

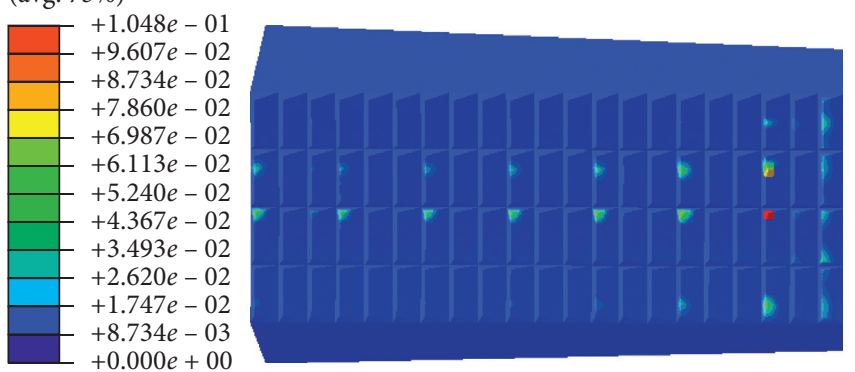

(d)

PEEQ

(avg: 75\%)

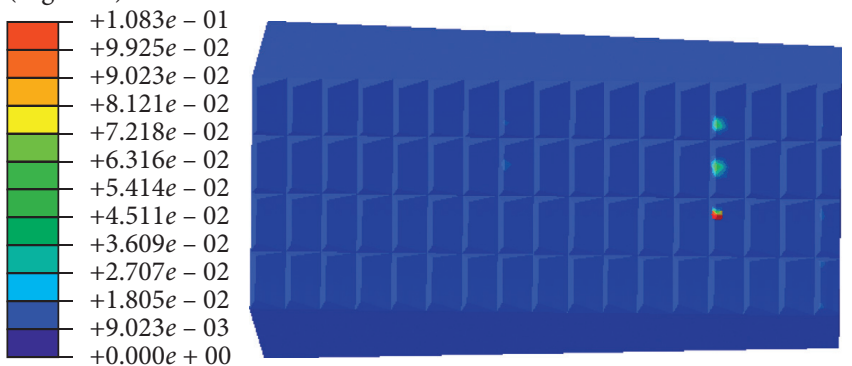

(f) 


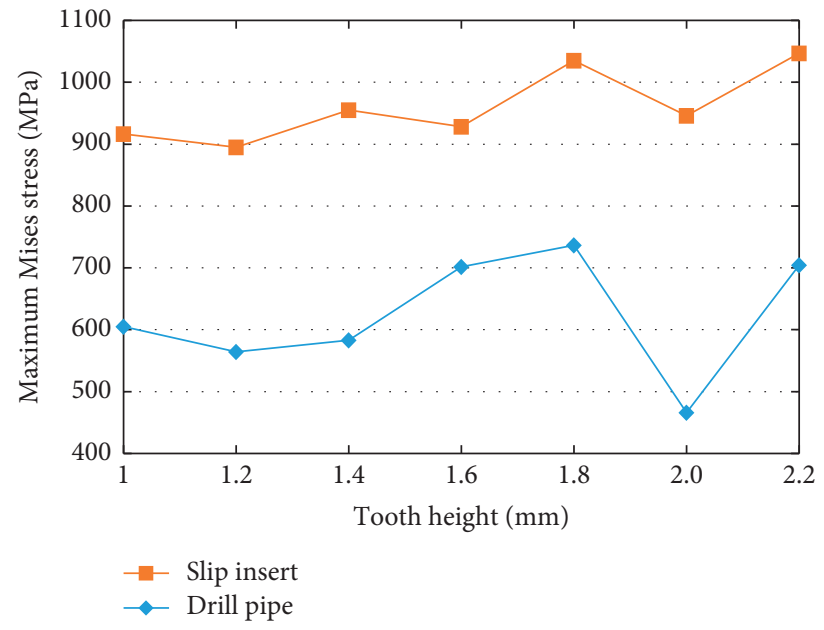

FIgure 18: Maximum Mises stresses on the DP and slip insert with different tooth heights.

S, Mises

(Avg: 75\%)

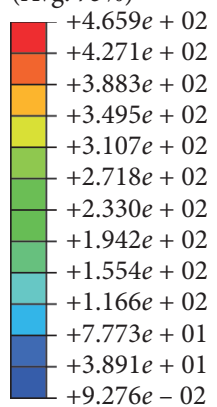

$+3.891 e+01$

S, Mises (avg: $75 \%$ )

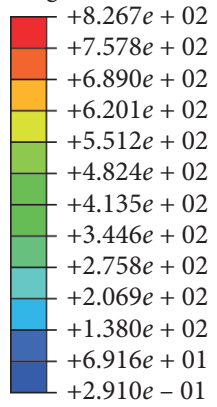

S, Mises

(Avg: 75\%)
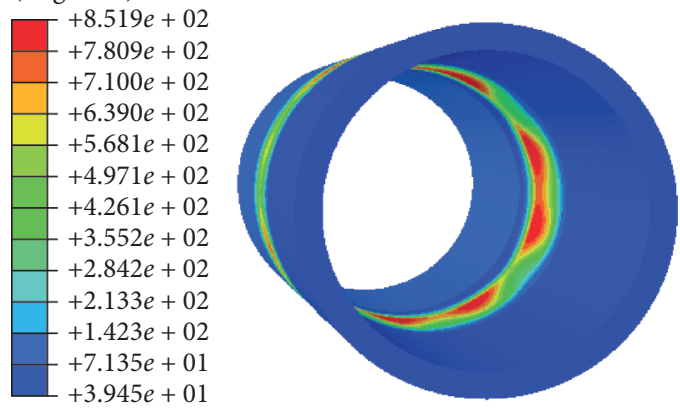

(e)

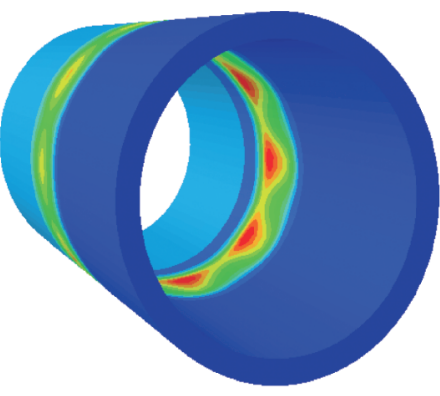

(a)

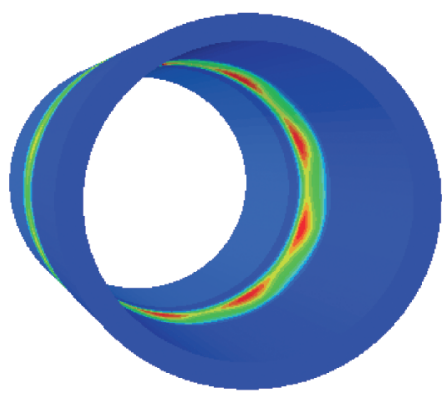

(c)
S, Mises

(avg: 75\%)
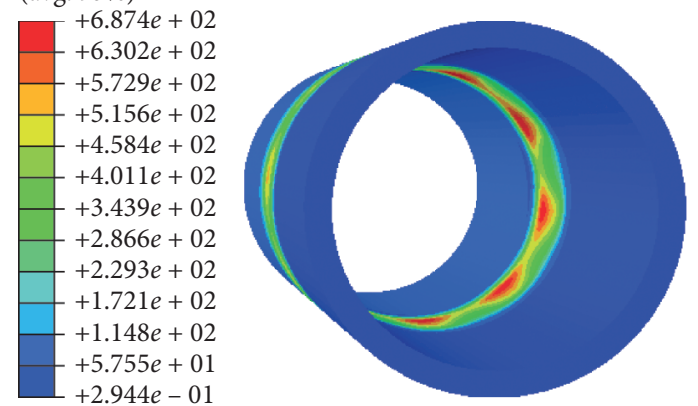

(b)

S, Mises (avg: 75\%)
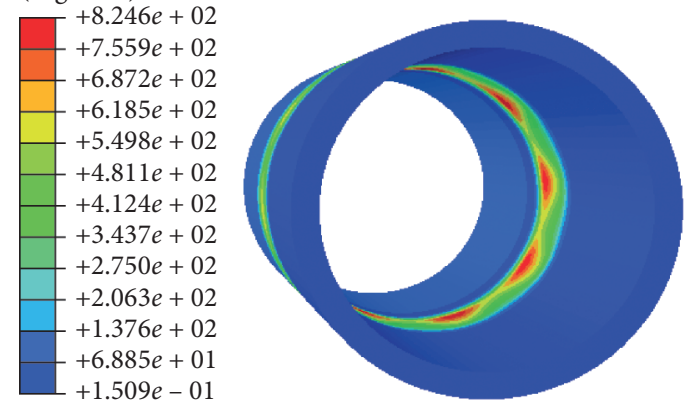

(d)

\section{S, Mises}

(avg: 75\%)
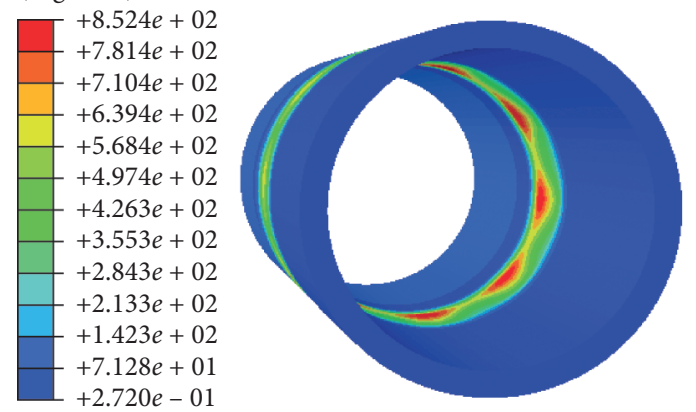

(f)

Figure 19: Continued. 

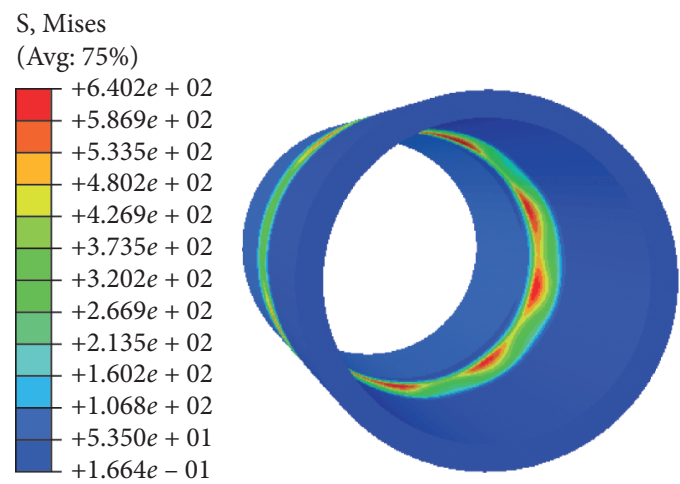

(g)

FIGURE 19: Stress contours of the DP (a)-(g) with different tooth chamfers ( $0 \mathrm{~mm}$ to $0.6 \mathrm{~mm}$ in steps of $0.1 \mathrm{~mm})$.

S, Mises

(Avg: 75\%)

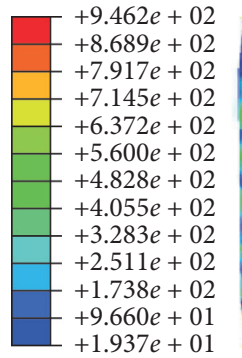

S, Mises

(Avg: 75\%)

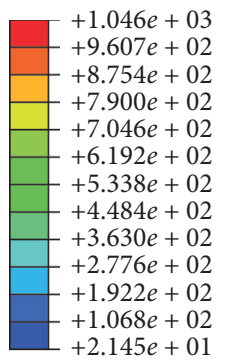

S, Mises

(avg: 75\%)
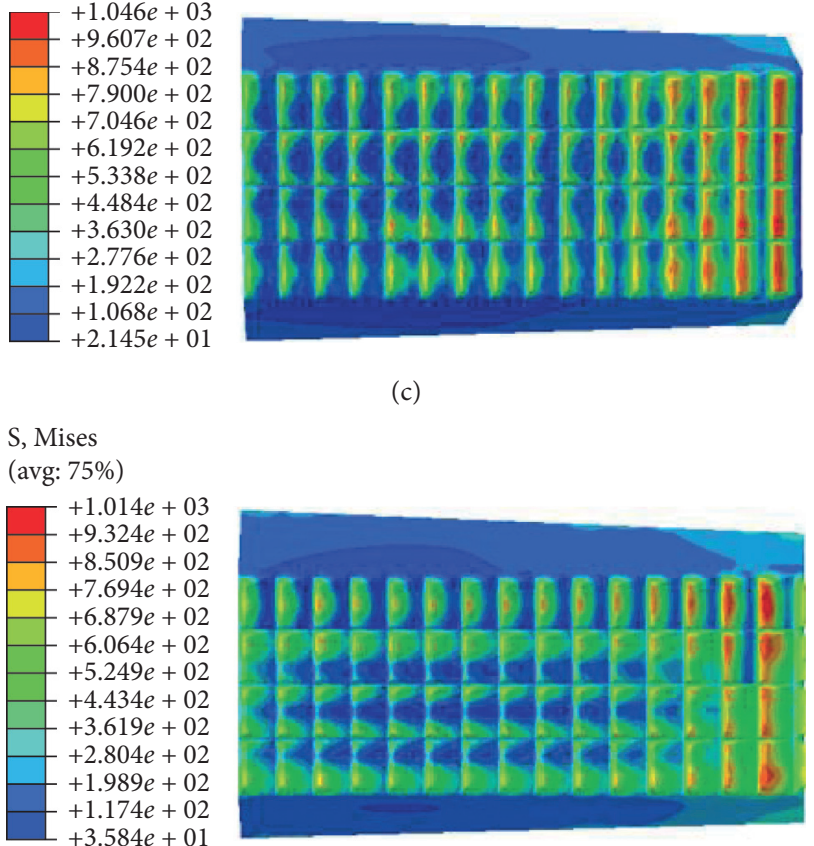

(c)

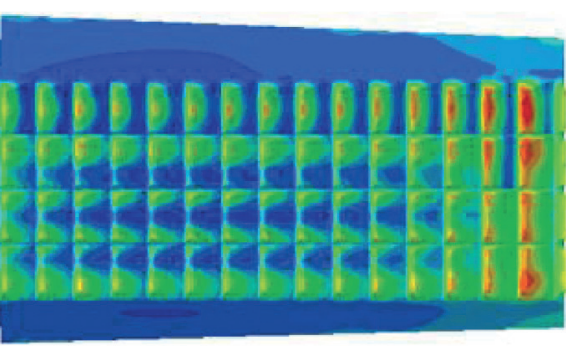

(e)

(a)
S, Mises

(Avg: 75\%)
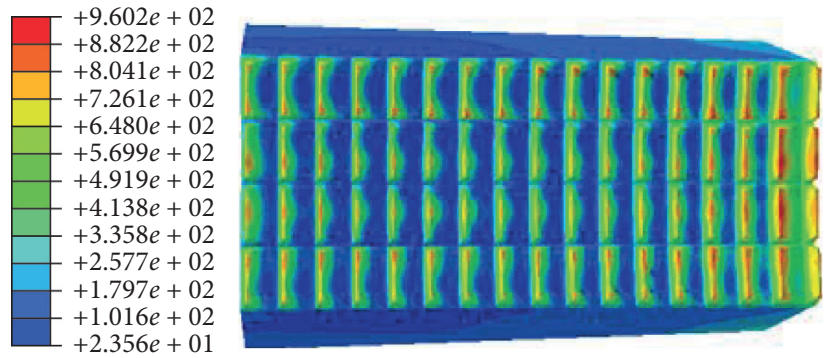

S, Mises

(Avg: 75\%)

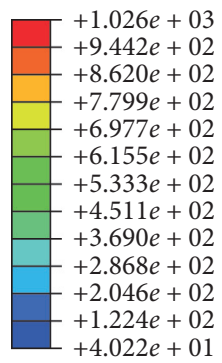

S, Mises

(Avg: 75\%)
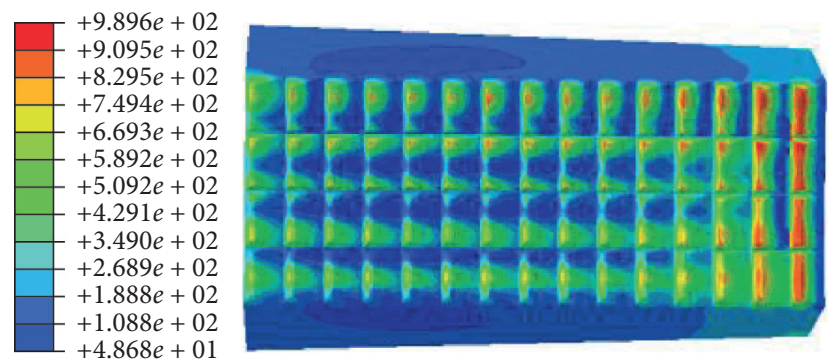

(f)

Figure 20: Continued. 
S, Mises

(Avg: $75 \%)$

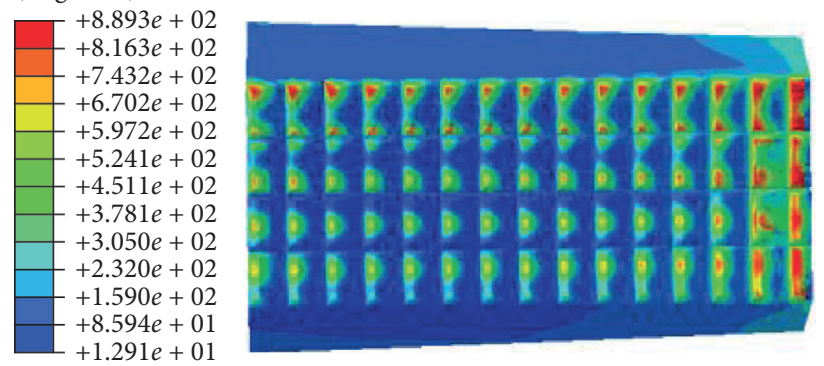

(g)

Figure 20: Stress contours of the slip insert (a)-(g) with different tooth chamfers $(0 \mathrm{~mm}$ to $0.6 \mathrm{~mm}$ in steps of $0.1 \mathrm{~mm})$.

PEEQ

(Avg: $75 \%)$

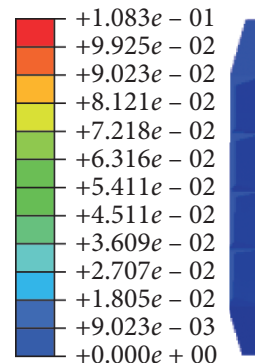

PEEQ

(Avg: 75\%)

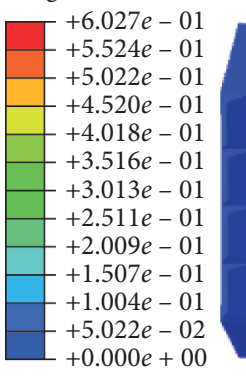

PEEQ

(Avg: 75\%)

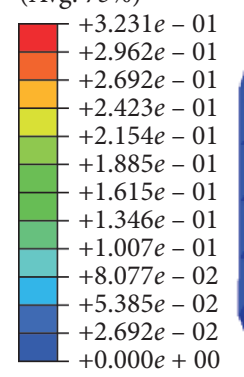

PEEQ

(Avg: 75\%)

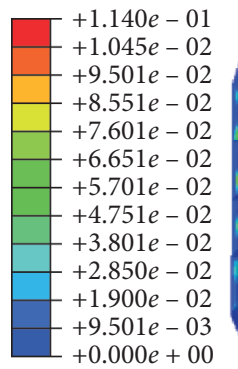

(a)

PEEQ

(Avg: 75\%)

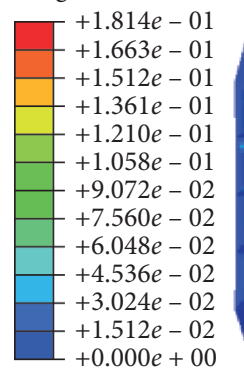

PEEQ

(Avg: 75\%)
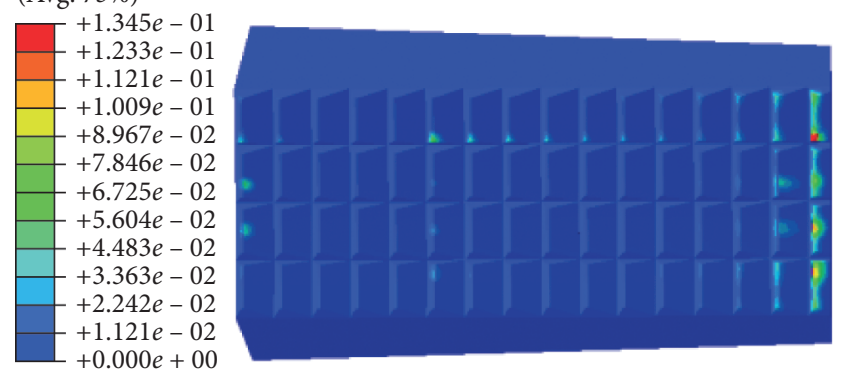

(f)

Figure 21: Continued. 


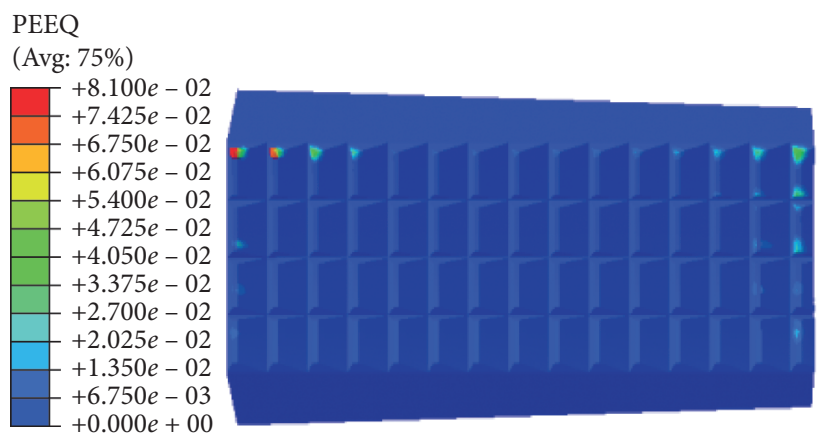

(g)

Figure 21: Equivalent plastic strain of the slip insert (a)-(g) with different tooth chamfers ( $0 \mathrm{~mm}$ to $0.6 \mathrm{~mm}$ in steps of $0.1 \mathrm{~mm})$.

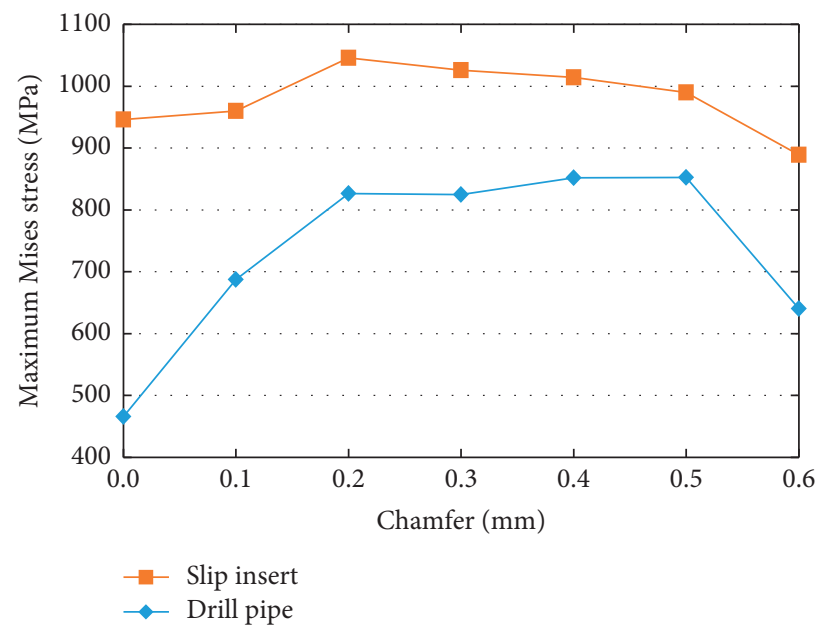

Figure 22: Maximum Mises stresses on the DP and slip insert with different chamfers.

3.3. Analysis of Tooth Chamfer. For the slip insert, the chamfer as shown in Figure 6 is an important factor in determining the effect of gripping. The sharp teeth may cause the DP to fail while blunt teeth may cause the DP to slip through the slip system. Consequently, selecting the correct tooth chamfer for the slip insert is critical to the performance of both the DP and the slip insert. Herein, we develop several variants of the FE model to solve this problem, wherein the FRA is $70^{\circ}$, the BRA is $30^{\circ}$, and the tooth height is $2 \mathrm{~mm}$. The stress contours of the DP and slip insert are shown in Figures 19 and 20, respectively. As can be seen from Figure 19, the stress of the inner surface of the DP is higher than that of the outer surface. For the slip inserts, the stress at the bottom end seems to be higher than that of other sections (Figure 20), which is similar to the contours presented above. Although the stress values of several DP are higher than other cases presented above, they do not exceed the yields value, and plastic deformation only occurs in the slip inserts. Figure 21 shows the equivalent plastic strain of the slip inserts, which shows that the plastic deformation appears on the edge of the slip inserts.

Figure 22 shows the relationship between the maximum Mises stress of the DP and slip inserts and the tooth chamfer. The simulation results show that as the chamfer is increased, the maximum Mises stress on the DP increases rapidly at first and then remains roughly stable and finally decreases rapidly. The maximum Mises stress of the slip insert increases slowly and then slowly decreases, and the overall stress amplitude does not fluctuate greatly. With zero chamfer, the maximum Mises stresses on the DP and the range of large plastic deformation of slip inserts are minimum, making zero the optimum chamfer value. This result may seem illogical because sharp teeth are easily viewed as sources of pipe cracking or insert failure. Also, we reason that it would be difficult to produce a slip insert with zero-chamfer teeth because of manufacturing errors. Nevertheless, a slip insert whose teeth have the smallest-possible chamfer should be selected. In summary, by analyzing the simulation results presented in this section, the following optimized parameter combination of the slip insert is obtained: a FRA of $70^{\circ}$, a BRA of $30^{\circ}$, a tooth height of $2 \mathrm{~mm}$, and zero chamfer.

\section{Conclusion}

Because of depleted oil and gas resources, deep, ultra-deep, and deep-water wells are becoming increasingly common, making drilling increasingly difficult and challenging. A very deep well means an extremely heavy DP, with the latter bearing a large axial tensile load that increases the possibility 
of the slip inserts damaging the DP. Herein, the parameters of a slip insert that are commonly used in drilling fields were optimized. First, a mechanical model of the slip-DP system was established and stress analysis was conducted by treating the DP as a cylinder acted on by external pressure. The results showed that the circumferential stress reaches its maximum value on the inner surface. Next, several versions of an FE model of the slip-DP system were developed to study how the slip-insert geometrical parameters affect the mechanical behavior of both the DP and the slip insert. Finally, orthotropic experiments of the numerical simulations on geometrical parameters were conducted based on the FE models. Herein, four geometrical parameters of the slip insert were studied, namely, the FRA, BRA, tooth height, and tooth chamfer. By analyzing the results of parameter sensitivity analyses, the following optimized parameter combination was obtained: an FRA of $70^{\circ}$, a BRA of $30^{\circ}$, a tooth height of $2 \mathrm{~mm}$, and zero chamfer. Of course, the results presented herein do not pertain to all slip systems and inserts because the present analysis was aimed at a specific type of slip insert. However, the research method presented herein is commonly applicable.

\section{Data Availability}

The data used to support the findings of this study are available from the corresponding author upon request.

\section{Conflicts of Interest}

The authors declare that they have no conflicts of interest.

\section{Acknowledgments}

This research was supported by the National Natural Science Foundation of China (no. 51904262 and no. 51674214), the China Postdoctoral Science Foundation (no. 43XB3793XB), the State Scholarship Fund of the China Scholarship Council (no. 201808515055), and the Scientific Innovation Group for Youths of Sichuan Province (no. 2019JDTD0017).

\section{References}

[1] K. Zaman and M. A. Moemen, "Energy consumption, carbon dioxide emissions and economic development: evaluating alternative and plausible environmental hypothesis for sustainable growth," Renewable and Sustainable Energy Reviews, vol. 74, pp. 1119-1130, 2017.

[2] M. Ming, Y.-N. Fu, and X.-F. Wang, "Decoupling, decomposition and forecasting analysis of China's fossil energy consumption from industrial output," Journal of Cleaner Production, vol. 177, pp. 752-759, 2018.

[3] C. Furlan and C. Mortarino, "Forecasting the impact of renewable energies in competition with non-renewable sources," Renewable and Sustainable Energy Reviews, vol. 81, pp. 1879-1886, 2018.

[4] L.-P. Tang and X.-H. Zhu, "Effects of the difference between the static and the kinetic friction coefficients on a drill string vibration linear approach," Arabian Journal of Science and Engineering, vol. 40, no. 12, pp. 3723-3729, 2015.
[5] I. Tomac and M. Sauter, "A review on challenges in the assessment of geomechanical rock performance for deep geothermal reservoir development," Renewable and Sustainable Energy Reviews, vol. 82, pp. 3972-3980, 2018.

[6] F. Amezaga, J. R. RialsR, and K. Heideck, "Landing string slip system: state-of-the-art design to minimize pipe crushing problems," in Proceedings of the SPE Asia Pacific Oil \& Gas Conference And Exhibition, Adelaide, Australia, October 2014.

[7] S. M. Zamani, S. A. Hassanzadeh-Tabrizi, and H. Sharifi, "Failure analysis of drill pipe: a review," Engineering Failure Analysis, vol. 59, pp. 605-623, 2016.

[8] U. B. Sathuvalli, M. L. Payne, P. V. Suryanarayana, and J. Shepar, "Advanced slip crushing considerations for deepwater drilling," in Proceedings of IADC/SPE Drilling Conference, Dallas, TX, USA, February 2002.

[9] K. Bybee, "Slip crushing considerations for deepwater drilling," Journal of Petroleum Technology, vol. 54, no. 5, p. 35, 2002.

[10] J. N. Brock, R. B. Chandler, M. J. Jellison, L. W. Sanclemente, R. J. Robichaux, and M. Saleh, "2 million-lbm slip-based landing string system pushes the limit of deepwater casing running," in Proceedings of the Offshore Technology Conference, Houston, TX, USA, April 2007.

[11] V. Flores, J. Franchi, S. Granger, and A. Vierke, "Innovative heavy landing system for ultradeep offshore: extended slip crush resistant tube, enhanced slip design and heavy weight carrier," in Proceedings of the 12th Offshore Mediterranean Conference And Exhibition, Galveston, TX, USA, September 2014.

[12] J. M. Jarski, F. J. Yousef, K. Vandervort, and G. C. Smith, "Development of ball-and-pocket gripping technology to overcome slip handling limitations," in Proceedings of the SPE Offshore Europe Oil And Gas Conference And Exhibition, Aberdeen, TX, UK, September 2011.

[13] G. E. Wilson, "A new drill pipe design virtually eliminates failures that result from slip damage," SPE Drill«Completion, vol. 12, no. 1, pp. 33-36, 1997.

[14] B. R. Simpson, M. L. Payne, M. J. Jellison, and B. A. Adams, "2,000,000-lbf landing-string developments: novel slipless technology extends the deepwater operating envelope," SPE Drilling \& Completion, vol. 20, no. 2, pp. 109-122, 2005.

[15] Y. Han, X.-H. Zhao, Z.-Q. Bai, and C.-X. Yin, "Failure analysis on fracture of a S135 drill pipe," Procedia Materials Science, vol. 3, pp. 447-453, 2014.

[16] M. T. Albdiry and M. F. Almensory, "Failure analysis of drillstring in petroleum industry: a review," Engineering Failure Analysis, vol. 65, pp. 74-85, 2016.

[17] H. Kinzel, K. Buettner, and M. Jaensch, "Gripping without slipping-the safe handling and running of chrome pipe with hard surfaces," in Proceedings of the IADC/SPE Asia Pacific Drilling Technology, Jakarta, Indonesia, September 2002.

[18] R. Verhoef and H. V. Rijzingen, "Tested and confirmed: the 1250-ton slip-proof landing string and slip system," in Proceedings of the SPE/IADC Drilling Conference And Exhibition, London, UK, March 2015.

[19] W. B. Reinhold and W. H. Spiri, "Why does drill pipe fail in the slip area?" World Oil, vol. 100, 1959.

[20] P. R. Paslay, P. D. Pattillo, U. B. Sathuvalli, and M. L. Payne, "A re-examination of drillpipe/slip mechanics," in Proceedings of the IADC/SPE Drilling Conference, Miami, FL, USA, February 2006.

[21] J. T. Vreeland, "Deformation of Drill Pipe Held in Rotary Slips," in Proceedings of the Petroleum Mechanical Engineering Conference, Kansas City, MI, USA, September 1961. 
[22] M. L. Payne, P. D. Pattillo, P. M. Driscoll, and U. B. Sathuvalli, "Experimental Investigation of Drillpipe Loaded in Slips," in Proceedings of the World Tribology Congress III, Washington, DC., USA, September 2005.

[23] A. Hayatdavoudi, "Elastic yield of casing due to elevator/ spider system," in Proceedings of the IADC/SPE Drilling Conference, New Orleans, LA, USA, March 1985.

[24] H. Zhang, D.-L. Gao, and H.-X. Tang, "Choice of landing string under ultra-deepwater drilling condition," in Proceedings of the CPS/SPE International Oil And Gas Conference And Exhibition, CHN, Beijing, China, June 2010.

[25] V. Tikhonov, M. Gelfgat, L. Ring, and O. Bukashkina, "Refinement of the drillpipe-slip mechanical model," in Proceedings of the SPE Russian Petroleum Technology Conference, Moscow, Russia, October 2017.

[26] M. M. Hossain, M. K. Rahman, S. S. Rahman, F. Akgun, and H. Kinzel, "Fatigue life evaluation: a key to avoid drillpipe failure due to die-marks," in Proceedings of the IADC/SPE Asia Pacific Drilling Technology, Jakarta, Indonesia, September 1998.

[27] L. Bordet, J. Franchi, S. Granger, and A. Vierke, "Innovative forging process allows safer and cost effective heavy duty landing string for deepwater applications," in Proceedings of the Deepwater Drilling \& Completions Conference, Galveston, TX, USA, September 2016.

[28] I. M. Gadala, M. A. Wahab, and A. Alfantazi, "Numerical simulation of soil physicochemistry and aeration influences on the external corrosion and cathodic protection design of buried pipeline steels," Materials \& Design, vol. 97, pp. 287299, 2016.

[29] I. M. Gadala, M. A. Wahab, and A. Alfantazi, "Electrochemical corrosion finite element analysis and burst pressure prediction of externally corroded underground gas transmission pipelines," Journal of Pressure Vessel Technology, vol. 140, no. 1, Article ID 011701, 2018.

[30] J.-Y. Ni, X.-W. Wang, J.-M. Gong, and M. A. Wahab, "Thermal, metallurgical and mechanical analysis of circumferentially multipass welded P92 steel pipes," International Journal of Pressure Vessels and Piping, vol. 165, pp. 164-175, 2018.

[31] X.-D. Qian, "Failure assessment diagrams for circular hollow section X- and K- joints," International Journal of Pressure Vessels and Piping, vol. 104, pp. 43-56, 2013.

[32] X.-D. Qian, " $\mathrm{K}_{\mathrm{I}}-\mathrm{T}$ estimations for embedded flaws in pipesPart I: axially oriented cracks," International Journal of Pressure Vessels and Piping, vol. 87, no. 4, pp. 134-149, 2010.

[33] X.-D. Qian, " $\mathrm{K}_{\mathrm{I}}-\mathrm{T}$ estimations for embedded flaws in pipesPart II: circumferentially oriented cracks," International Journal of Pressure Vessels and Piping, vol. 87, no. 4, pp. 150-164, 2010.

[34] H.-S. Zhao, S. T. Lie, and Y. Zhang, "Fracture assessment of mismatched girth welds in oval-shaped clad pipes subjected to bending moment," International Journal of Pressure Vessels and Piping, vol. 160, pp. 1-13, 2018.

[35] L.-P. Tang, X.-H. Zhu, J.-H. Li, and C.-S. Shi, "Optimization analysis on the effects of slip insert design on drill pipe damage," Journal of Failure Analysis and Prevention, vol. 16, no. 3, pp. 384-390, 2016.

[36] Simulia. ABAQUS, version 6.11, https://www.simulia.com, 2011.

[37] Z.-L. Xu, Elastic Mechanics, Higher Education Press, Beijing, China, 4th edition, 2006. 